University of San Diego

Digital USD

1987

\title{
The Effect of Cooperative Learning on the Spelling Skills, Self- Concept, and Locus of Control of Below Average Learners
}

Lyle Rangel EdD

University of San Diego

Follow this and additional works at: https://digital.sandiego.edu/dissertations

Part of the Leadership Studies Commons

\section{Digital USD Citation}

Rangel, Lyle EdD, "The Effect of Cooperative Learning on the Spelling Skills, Self-Concept, and Locus of Control of Below Average Learners" (1987). Dissertations. 493.

https://digital.sandiego.edu/dissertations/493

This Dissertation: Open Access is brought to you for free and open access by the Theses and Dissertations at Digital USD. It has been accepted for inclusion in Dissertations by an authorized administrator of Digital USD. For more information, please contact digital@sandiego.edu. 
THE EFFECT OF COOPERATIVE LEARNING ON THE

SPELLING SKILIS, SELF-CONCEPT, AND LOCUS OF CONTROL

OF BELOW AVERAGE LEARNERS

by

Lyle Rangel

A dissertation submitted in partial fulfillment

of the requirements for the degree of

Doctor of Education

University of San Diego

1987

Dissertation Committee

Edward Kujawa, Ph. D., Director

Robert L Infantino, Ed. D.

Patricia Lowry, Ph. D. 
(C) 1987

LYLE RANGEL

ALL RIGHTS RESERVED

Reproduced with permission of the copyright owner. Further reproduction prohibited without permission. 


\begin{abstract}
Study
The Effect of Cooperative Learning on the Spelling Skills, Self-Concept, and Locus of Control of Below Average Learners
\end{abstract}

by

Lyle Rangel

University of San Diego

THE PROBLEM A pilot study had shown that below average learners have commonalities in their learning styles. Since the literature had demonstrated that matching students' learning style with a compatible teaching approach could improve the academic performance of children, this study attempted to determine what the impact of teaching cooperatively, a teaching approach that closely matched the preferred learning style of the below average learners, would have on such learners. The impact of the teaching strategy was evaluated through changes in spelling scores, in self-concept and in locus of control. Further, the impact on boys and girls was monitored to determine if either gender would respond differently to this teaching approach. METHOD A non-equivalent control group design was used to organize the study. Six teachers were randomly assigned to either an experimental or control group from two public school sites. The experimental teachers received inservice in cooperative learning. At the same time, the students of both the experimental and control group teachers were pretested in terms of spelling achievement, self-concept and locus of control. The experimental teachers then taught spelling using cooperative leaming during a six week treatment period. At the conclusion of the six weeks, the students were posttested. 
ANALYSIS OF DATA The data was analyzed using the analysis of covariance procedure in order to evaluate the three null hypotheses and their sub-hypotheses.

RESULTS Two of the three null hypotheses were rejected. The results indicated that the experimental group significantly outperformed the control group in spelling achievement with both the experimental males and females showing significantly greater growth in spelling than the control males and females, respectively. On the locus of control measure, there was a significant difference between the experimental and the control groups, favoring the experimental group, due mainly to the performance of the experimental females. On the self-esteem measure, the experimental males scored significantly higher than control males. Analyses to determine the effect that the school site had on the performances of the students did not reflect a specific effect for school site. When Q1 students (those scoring below the twenty-fifth percentile on their overall score on the Comprehensive Test of Basic Skills) were compared with Q2 students (students scoring between the twenty-fifth percentile and below the fiftieth percentile on their overall score on the Comprehensive Test of Basic Skills) no systematic effect because of academic level (Q1 or Q2) was found. 
The researcher wishes to express his appreciation and gratitude to the following people.

Dr. Patricia Lowry, my advisor, for "hanging in there" with me throughout my program of study. More specifically, for her patience, her insight, and her willingness to work through ideas with me.

Dr. Edward Kujawa and Dr. Robert Infantino of my Supervisory Committee for their meticulous reviews of my proposal and dissertation drafts and their long time encouragement.

Dr. Raymond Brandes for always being available to share ideas and provide intellectual challenges.

Thanks to Joshua Tull, Freddie Jackson, and Judy Uriostegui for their assistance in collecting my data and their leadership in promoting cooperative learning, and to the many teachers and other school personnel who provided me with my data.

A special thanks to my friend, Dr. Daniel Watson, for the hours he spent with the data and the computer. And for the hours we spent talking through dissertation ideas and for always taking time to be available.

Thanks to Darlene Watson, Alice Silber, and Barbara Smith, most efficient handlers of messages West of the Mississippi, for the many weekends, evenings, and early mornings they took my messages. 
LIST OF TABLES

Chapter

1. Statement of the Issue . . . . . . . . . . 1

Introduction . . . . . . . . . . . . . 1

Focus on Low Achieving Students . . . . 3

Purpose of the Study . . . . . . . . . . 4

Null Hypotheses . . . . . . . . . 8

Significance of the study . . . . . . . . 9

Cooperative Learning . . . . . . . . 12

Definition of Terms . . . . . . . . . 14

Summary . . . . . . . . . . . . 16

Chapter

2. Review of the Literature . . . . . . . . . 18

Introduction . . . . . . . . . . . . 18

Learning styles. . . . . . . . . 18

Models of Learning Styles . . . . . 20

Learning Style and Student Performance . 20

Matching Learning Style and Teaching

Methodology . . . . . . . . . . . 29

Impact on Alternate Areas . . . . . . 30

Cooperative Learning . . . . . . . . 31

Types of Cooperative Learning Classroom

Models . . . . . . . . . . . . 32 
Outcomes of Cooperative Learning Strategies . . . . . . . . . . . . 34 Summary . . . . . . . . . . . . 40 40

3. Research Design and Methodology . . . . . . 42

Introduction . . . . . . . . . . . . 42

Sites . . . . . . . . . . . 42

The Setting . . . . . . . . . . . . 44

Subjects . . . . . . . . . . . 46

Curriculum Design . . . . . . . . 47

Pilot Study . . . . . . . . . . 50

Instrumentation . . . . . . . . . . . 52

Piers-Harris Self-Concept Inventory . . 53

Intellectual Achievement Responsibility

Scale... . . . . . . . . . 54

Criterion Referenced Instrument . . . 55

Procedures . . . . . . . . . . . 55

Overview . . . . . . . . . . . 55

Identification of Teachers . . . . . 56

Teacher Training . . . . . . . . 57

Treatment . . . . . . . . . . 59

Testing of students . . . . . . . 60

Training of students . . . . . . . 60

Implementation Checks . . . . . . . 60

Experimental Design . . . . . . . . 61 
Chapter

Page

Statistical Analysis . . . . . . . .

62

Hypothesis One . . . . . . . . . . 62

Hypothesis Two . . . . . . . . . . 63

Hypothesis Three . . . . . . . . . 64

Limitations . . . . . . . . . . . 65

Human Subjects Permission . . . . . 66

Summary . . . . . . . . . . . . . 67

4. Results . . . . . . . . . . . . 68

Introduction . . . . . . . . . . . 68

Restatement of the Purpose . . . . . . 68

Analyses of the Hypotheses . . . . . . 68

Null Hypothesis One . . . . . . . . 68

Null Hypothesis Two . . . . . . . . 73

Null Hypothesis Three . . . . . . . 77

Related Analyses . . . . . . . . . 81

Impact of Site . . . . . . . . . 82

Academic Level . . . . . : . . . . 87

Summary • • • • • • • . • . • . 93

5. Summary, Conclusions, Discussion and

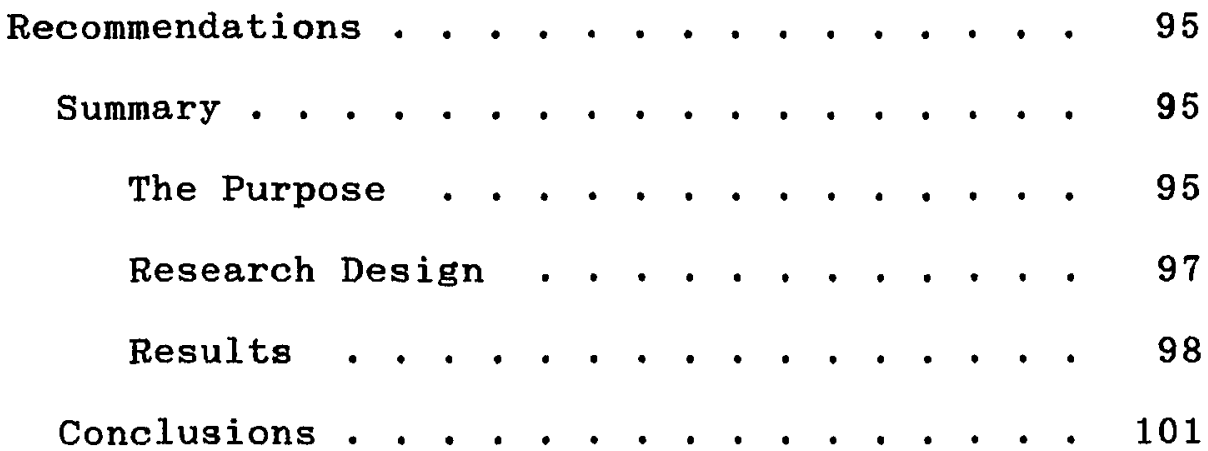


Discussion . . . . . . . . . . . 102

Spelling . . . . . . . . . . 103

Self-Esteem . . . . . . . . . 107

Locus of Control . . . . . . . . 110

The Role of the Instructional Leader . . 112

Other Findings . . . . . . . . . . . . . . 114

School Site . . . . . . . . . . 114

Academic Level . . . . . . . . . 115

Conclusion . . . . . . . . . . 115

Recommendations . . . . . . . . . . 117

Final Statement . . . . . . . . . 119

REFERENCES . . . . . . . . . . . . . . . . . 121

APPENDICES • . . . . . . . . . . . . . . . . 129

Appendix A, Intellectual Achievement Responsibil-

ity Questionnaire . . . . . . . . . . . 130

Appendix B, The Self-Esteem Test . . . . . . . 134

Appendix C, Parent Permission Letters . . . . . 138 


\section{LIST OF TABLES}

Table

Page

1. Percentages of Students Working at the Four

Quartiles on the California Achievement

Program Basic Skills Test Written Language

Subtest at the Two School Sites . . . . . 44

2. Percentages of Third Grade Students Who

Expressed Various Attitudes of Liking

Written Language at the Two Sites . . . . 44

3. Diagram of the number of Teacher by Experimental and Control Groups at Each Site . . 45

4. Distributions of the Experimental and Control

Groups at the Two Sites by Gender of the Students . . . . . . . . . . . 47

5. Pretest and Posttest Means on the Spelling Test for the Treatment Groups and the Genders. . 69

6. Gain Scores for the Spelling Test Comparing Treatment Groups and Genders . . . . . 70 
7. Analysis of Covariance and Test of Simple Main Effects for the Spelling Test Comparing the Performance of the Treatment Groups and the Genders . . . . . . . . . . . .

8. Pretest and Posttest Means for the Treatment Groups and the Genders on the Piers-Harris Self-Concept Inventory . . . . . . . 74

9. Gain Scores for the Treatment Groups and Genders on the Piers-Harris Self-Concept Inventory . . . . . . . . . . . . .

10. Analysis of Covariance and Test of Simple Main Effects Comparing the Performance of the Treatment Groups and the Genders on the Piers-Harris Self-Concept Inventory . . .

11. Pretest and Posttest Means for the Treatment Groups and the Genders on the Intellectual Achievement Responsibility Scale . . . .

12. Gain Scores for the Treatment Groups and Genders on the Intellectual Achievement Responsibility Scale . . . . . . . . 
13. Analysis of Covariance and Test of Simple Main Effects Comparing the Performance of the Treatment Groups and the Genders on the Intellectual Achievement Responsibility Scale . . . . . . . . . . . . .

14. Pretest and Posttest Means and Gain Scores for the Treatment Groups at the Sites on the Spelling Test . . . . . . . . . . . .

15. Analysis of Covariance and Test of Simple Main Effects Comparing the Performance of the Treatment Groups and the Sites on the Spelling Test . . . . . . . . . . .

16. Pretest and Posttest Means and Gain Scores for the Treatment Groups at the Sites on the Intellectual Achievement Responsibility Scale . . . . . . . . . . . . . .

17. Analysis of Covariance and Test of Simple Main Effects on the Intellectual Achievement Responsibility Scale Comparing the Performance of the Groupg at the sites . . . . . . . . . . . 86 
18. Crosstabulation of Student Grouping and Student Academic Level . . . . . . 88

19. Pretest and Posttest Means and Gain Scores for

the Treatment Groups at the Two Academic

Levels on the Spelling Test . . . . . . 89

20. Analysis of Covariance and Test of Simple Main Effects on the Spelling Test Comparing the Performance of the Groups at the Two Academic Levels . . . . . . . . . . 90

21. Pretest and Posttest Means and Gain Scores for the Treatment Groups at the Two Academic Levels on the Intellectual Achievement Responsibility Scale . . . . . . . . 92

22. Analysis of Covariance for the Intellectual Achievement Responsibility Scale Comparing the Performance of the Groups and the Two Academic Levels . . . . . . . . .

23. Summary of Results for the Null Hypotheses . 100 
CHAPTER ONE

Statement of the Issue

Introduction

Over the past 15 years there has been an increasing amount of research examining the role of learning styles in educational settings. Learning styles have been defined (Dumn, 1984; Guild and Garger, 1985) as an educational approach based on the belief that each child had a specific way of learning that could enhance or impede the child's academic achievement. This educational approach further contended that the closer the child's learning style matches the teaching methodology, the better the child would learn.

The research on this educational strategy had focused on identifying various learning styles (Dunn, Dunn \& Price, 1982; Gregorc, 1979; Keefe, 1982), on how to best match the styles of students' learning and teachers' instructing (Ball, 1982; Dunn, 1983), and on the impact of programs in which teaching and learning styles were aligned (Cavanaugh, 1981; Dunn, 1981; Jenkins, 1982). However, these early studies on children have centered primarily on gifted children (Cross, 1982; Stewart, 1981; Wasson, 1981) or on high school students (Carruthers \& Young, 198n; Lynch, 1981).

There have been fewer studits focused on the elementary level. Those studies evaluating learning styles in elementary students have primarily identified the dominant styles of various groups. Some studies have begun to identify the differing styles for the student achieving below grade level (Pizzo, 1981; Krimski, 1982). The major limitation of these 
research efforts had been their focus on the identification of styles and not on the efficacy of the learning style model.

However, the lack of research had not reduced continued support for the match of teaching methodology or style to learning styles. For example, Guild and Granger (1985) argued that teachers should match their teaching styles with student learning styles to provide more appropriate instruction for a segment or the total class. However, only a limited number of teachers attempted to match teaching and learning styles, i.e., they made a conscious effort to provide instruction in a manner that best matched the individual learning style of the child. The use of matching had been stymied in a great part due to the needs of the system to have uniform and standard approaches to instruction (Guild and Granger, 1985).

The problem of matching the students' learning styles with a teaching strategy was further compounded by the existence of differing teaching styles. Just as styles of learning have been identified by researchers, so styles of teaching have been likewise identified. Teachers have often used differing teaching styles throughout the course of any day, but every teacher usually has had one or two styles that predominated (Butler, 1984). Butler stated that teaching style was as influential on student learning as were the daily activities in the classroom.

There was a lack of supporting research in the specific area of matching the teacher's mode of instruction or style to the learning styles of the student. This had occurred, because the researchers have not centered on the academic changes that occurred when a student 
received instruction matched to the student's learning styles. Instead, the great majority of studies have dwelt on delineation of the differing learning styles (Dunn, 1983).

Focus on Low Achieving Students

This present study was aimed at extending the learning style literature by examining the results on students when learning and teaching styles were matched. More specifically, this current effort evaluated the impact of matching a teaching approach with the learning styles of students who were below average in their academic performance. This large group instructional strategy was cooperative learning. Cooperative Learning had been defined (Johnson \& Johnson, 1975; Kagan, 1985; and Slavin, 1980) as an educational approach that enhanced the interactions of the students for academic improvement. It was different from group discussion and other group educational approaches due to its emphasis on the development of learning teams limited to four to six students. In a cooperative learning structure, these teams were responsible for and were rewarded for the academic improvement of each team member,

The rationale for this current study was straightforward. In the typical classroom, teachers did not have the time to individualize instruction to match or meet the individual needs or styles of each student. But learning style research had shown that matching the teachers' teaching styles and the students' learning styles was beneficial to the academic performance of the average student (Guild and Granger, 1985; Keefe, 1982; Shea, 1983; Virostko, 1983). As a result, a general question emerged. Would the use of a large group instructional 
strategy that closely approximates the preferred learning styles of the students have an impact on the academic performance of these atypical students?

Below average students are the target group of this study for four reasons. First, ethnic minority students were increasing in noticeable numbers throughout almost every classroom. Since ethnic minorities often performed below the average of many classes academically (Jensen, 1982), a teaching strategy that would help below average students would also provide an alternative teaching methodology for some ethnic minority students.

Second, ethnic minority children often enter classrooms with learning styles that differ markedly from those of the typical middle class, white child (Kagan, 1980, 1983, 1985). Since such difference in learning style might have tremendous impact on the academic success of these children, this present study could offer teachers a more appropriate teaching technique to use with below average students.

Third, teashers often have difficulty providing appropriate instruction for the group of "slower" learners in their classrooms. This present effort attempted to evaluate if preferred learning styles could be matched by using cooperative learning as a teaching style or strategy, and to determine if this match would improve the acadenic performance of these atypical students, particularly in the area of spelling.

Lastly, it was also speculated that there was a wider impact of matching teaching style to student learning styles beyond the improvement of academic performance. This difference should be noticed 
in self-concept and locus of control of the students who experienced the matching of teaching and learning styles. There were several researchers who supported evaluating both self-concept and locus of control (Autry and Langenbach, 1986; Shavelson and Bolus, 1982).

Traditionally, in the area of self-concept, there has been a relatively strong, positive relationship between academic achievement and self-concept. Furthermore, the self-concept of these below average learners has continually been significantly lower than that of higher achieving students (Wylie, 1979). Moreover, Shavelson and Bolus (1982) concluded that this lower attitude interacted with and seemed to be a causative factor of academic performance for many of these students.

The interest in self-concept and achievement stemmed from the apparent belief that children's feelings about themselves were key factors in school achievement. The assumption of many theorists seemed to be that the child's developmental needs, including positive self-concept, were one of the bases for educational progress (Potterbaum, Keith, Ehly, 1986). In this current study, it was believed that if there was a more positive match between the teaching strategy of the teacher and the learning style of the student, then the students would feel more positive about themselves and their self-concept would improve.

Evaluating locus of control also appeared to be an important area for study. Locus of control research has been associated with the investigation of the perception of causality, the individual's judgment of the causes of outcomes. The degree to which individuals perceived that their own behavior was the controlling factor in receiving rewards, 
reinforcements and academic performances, the more that the person was identified as internally oriented (Autry \& Langenbach, 1986).

Internally oriented individuals believed that the reinforcements they received were primarily a result of their own behavior, ability, effort or personal characteristics. Students at the external end of the locus of control continuum attributed their control of their reinforcements to forces outside of themselves: luck, chance, fate and task difficulty (Weiner, 1972). Since there would be a better match between the style of the student and the strategy of the teacher, it was believed that the atypical students in the experimental condition would perceive this change as a reduction in the difficulty of the academic task. As a result, it was necessary to examine their locus of control scores to determine if the students did change their responding in this area. In addition, this difference in teaching style would create less conflict between the students and the teacher which could also affect locus of control scores.

The examination of gelf-concept and locus of control was seen as being very important for another reason. This reason was exemplified by the research of Talmage, Pascarella, \& Ford (1984). After studying cooperative learning efforts over a three year period, these researchers concluded that, due to their primary focus on academic outcomes, they had not captured the dimensions of cooperative learning that fostered academic growth. As a result, they suggested that future research efforts examine more than the academic arena. Therefore, self-concept and locus of control were examined to determine the broader impact of cooperative learning. 
As a final note, this current effort also examined the results of the intervention separately for boys and girls. As reported by Webb (1984), males in cooperative groups outperformed females. Webb believed that this was due to the fact that, in her junior high student population, males were more able to get their questions answered and information mastered than were females. This present effort extended the research on the role of gender in the academic achievement of elementary age students who were in cooperative groups.

\section{Purpose of the Study}

This investigation was designed to study the influence of cooperative learning, and, in particular, student teans-achievement divisions, a specific cooperative learning strategy, on below average learners' spelling achievement, self-concept and locus of control. This study was directed by the following exploratory questions:

1. Could the spelling achievement of below average students be raised by better matching their learning styles through the use of a cooperative learning approach, as evidenced by spelling test scores?

2. Would the self-concept of the below average students change as a function of involvement in a cooperative learning environment, as measured by the Piers-Harris Self-Concept Scale (Piers, 1969)?

3. Would the internal-extemal beliefs (locus of control) be modified through exposure to the cooperative learning experienced, as measured by the Intellectual Achievement Responsibility Questionnaire (Crandall, et. al., 1965)?

4. Would boys and girls, who experienced cooperative learning, differ in their spelling achievement, in their self-concept and in their 
intermal-external beliefs from boys and girls who did not experience cooperative learning?

\section{Null Hypotheses}

Based on these general research questions, null hypotheses were developed. They were:

$H_{0} 1$. There will be no significant difference in spelling achievement between a group of below average students in the third grade who experienced cooperative learning and control group students who did not experience cooperative learning.

Ho1.1 There will be no significant difference in spelling achievement between a group of below average males in the third grade who experienced cooperative learning and control group males who did not experience cooperative learning.

$\mathrm{H}_{0} 1.2$ There will be no significant difference in spelling achievement between a group of below average females in the third grade who experienced cooperative learning and control group females who did not experience cooperative learning.

$H_{0}$. There will be no significant difference in self-concept between a group of below average students in the third grade who experienced cooperative learning and control group students who did not experience cooperative learning.

$\mathrm{H}_{0} 2.1$ There will be no significant difference in self-concept between a group of below average males in the third grade who experienced cooperative learning and control group males who did not experience cooperative learning. 
Ho2.2 There will be no significant difference in self-concept between a group of below average females in the third grade who experienced cooperative learning and control group females who did not experience cooperative learning.

Ho3. There will be no significant difference in the locus of control measure between a group of below average students in the third grade who experienced cooperative learning and control group students who did not experience cooperative learning.

Ho3.1 There will be no significant difference in the locus of control measure between a group of below average males in the third grade who experienced cooperative learning and control group males who did not experience cooperative learning.

$\mathrm{H}_{0}$ 3.2 There will be no significant difference in the locus of control measure between a group of below average females in the third grade who experienced cooperative learning and control group females who did not experience cooperative learning.

\section{Significance of the Study}

This study was organized to examine the impact of cooperative learning on the academic performance and on related areas for below average learners. As such, this study was based on an earlier pilot study conducted by the researcher, which is sumnarized in Chapter Three. The results of the pilot indicated that the preferred learning styles of below average students were reagonably well matched with cooperative learning strategies. And, if the learning style needs of this group of learners could be met through the use of cooperative learning, then 
teachers would have an important tool for addressing this particular group of students.

The improvement of education for the below average student was an important area of study for several reasons. First, millions of dollars are expended every year through governmental programs to remediate the difficulties of students who are below grade level. At the same time, critics, such as Jensen (1981), continued to state that this effort was wasted due to equivocal outcomes of these programs. If the matching of the below average students' learning styles with a group teaching strategy (which paralleled their general learning styles) did alter academic performance, then, perhaps, better matches in teaching strategy and learning styles might be considered to make these remedial efforts more effective.

Second, the below average student has been one student that the typical teacher had felt was not learning as much as might be expected. This present study provides information which could alter the teaching approaches used with this type of student. Such information would improve the education of these individuals and facilitate the teachers' efforts.

Third, this study would provide data on the ease and facility of matching teaching approach and learning style through the use of a group teaching strategy. That is to say, this study questions if the alteration of teaching style by the use of a teaching strategy that closely approximated the learning style of the below average student would alter the classroom performance of this group of children. 
Furthermore, it was hypothesized that the below average learner had usually done poorly in traditional classrooms due to the conflict between teaching style and learning style (Guild and Granger, 1985). Therefore, a search was conducted to find a well designed teaching approach that had a strong research base, could be easily taught to teachers, and allowed the teacher to teach to the total group. This approach, however, must also address the needs of below average learners and closely match the learning style of these below average learners.

One of the major weaknesses of the learning style approach, in terms of instruction, was its emphasis on teaching through the "individual's learning style". This limitation appeared to support the search for an effective group teaching methodology because it meant that pupils must either be instructed individually or grouped by one of their potential learning styles. Such styles could include, for instance, a preference for a highly lighted learning environment, access to food during the class time, or by the more commonly recognized learning styles (visual, kinesthetic, or auditory inputs), with a minimum of 24 styles being recognized (Dunn, 1983). This emphasis implied that a teacher would have to prepare individualized or small group lessons addressing the learning styles of each child or each group of children for every lesson, which could be an overwhelming task for almost any instructor. This point was supported by Copenhaven's (1979) study which illustrated that the typical teacher could not cope with the many styles within the classroom.

On a practical note, teachers have even had extensive difficulty individualizing their instruction for the topics of reading, mathematics 
and writing. This seemed to imply that matching learning styles and teaching approach on every trait or even on important traits for each child or small groups of children would not be logistically possible for most teachers. Additionally, the literature on effective teaching had been showing that large group instruction was more effective than individualization (Medley, 1977; Rosenshine, 1979; Good, Grouws, \& Ebmeir, 1983). As a result, there appeared to be a need to determine if matching learning styles could be accomplished through the use of a teaching strategy that allowed large group instruction that approximated the general learning styles of a select group of students.

Therefore, in place of matching solely on one or two traits, the present study attempted to match learning styles and teaching approaches by examining the impact of a teaching strategy that addressed the major profile features of the learning styles of below average students. Since teachers frequently taught in group settings, a teaching approach that addressed the needs of these below average learners and would be appropriate for a "group" presentation seemed most appropriate. Cooperative Learning

One of the most widely resuarched "group" teaching approaches for the average students currently being used has been cooperative learning (Aronson, 1978; Slavin, 1980). This approach has an extensive research base and materials have been developed both for inservicing teachers and for use in the classroom. Further, Kagan (1985) pointed out that cooperative learning had several specific impacts:

1) Greater task structure and clarity;

2) The subdivision of the learning unit into masterable 
parts;

3) Greater frequency and variety of practice;

4) The rewards for learning were more frequent and immediate;

5) The rewards were peer based and were peer oriented;

6) The teacher was in a better position to move around the classroom giving feedback to students;

7) Students were more active and self-directing.

Cooperative learning had shown itself to be effective in helping a variety of typical children do better academically and socially (Slavin, 1980). Its distinctive characteristics outlined above indicated it to be an approach that a teacher could implement for better assisting the atypical or below average learners.

Overall Impact of Cooperative Learning. An important point that this study addressed was the impact of cooperative learning not only on the academic performance of children but also on the other equally important areas, locus of control and self-concept. Papert (1980) and Pukey (1969) pointed out how important self-concept and self-confidence were in the educational behavior of the child. Likewise, Fennema (1982) demonstrated that learning how to "control the outcomes of achievement striving", that is, to have an internal locus of control, leads to better performance on cognitive tasks.

Finally, this research provides validation of the cooperative leaming model (Johnson \& Johnson, 1984; Kagan, 1985; and, Slavin, 1980) for its application for other educational purposes. Historically, interest in cooperative learning has been strongly focused on successful 
integration efforts within schools and the building of cross-racial friendships (Slavin, 1985). This current effort did not examine the effects in terms of integration or friendship building but approached cooperative learning as a methodology for addressing the needs of the low achieving student within the typical classroom.

\section{Definition of Terms}

AVERAGE LEARNERS: Average learners, for this study, refers to those children who performed above the 50th percentile and below the 98th percentile (California Administrative Code, Title V Regulations, 1986) on their scores on the Comprehensive Test of Basic Skills. Teachers identified these as their average children who needed little extra help to profit from the learning experience.

BELOW AVERAGE LEARNERS: Below average learners refers to those children who performed below the 50th percentile in terms of the Comprehensive Test of Basic Skills total battery score. Teachers referred to these students as atypical learners, below average students, or hard to reach children. These children, by definition (California Administrative Code, Title V Regulations, 1986), did not qualify for special education but 
continued to perform below the average of most classrooms within many districts.

BELOW GRADE LEVEL:

A term used for identifying the academic

performance of children. Children who scored

below the 50th percentile were considered to be

below grade level (California State Department

of Education, 1983). Children, who fell in this

range, could also be called below average

learners or below grade level students.

COOPERATTVE LEARNING: Cooperative Learning is an educational approach

that enhances the interactions of the students

for academic improvement. It differs from group

discussion and other group educational

approaches due to its emphasis on the

development of learning teams limited to four to

six students. These teans are given greater

responsibility through training each other for

the academic improvement of each team member

than in a typical classroom, and are rewarded

for the improvement of each team member.

LEARNING STYLE:

An educational approach stating that each child

has a specific style of learning that could

enhance or impede the child's acquisition of

academic achievement. This approach believes

that the closer the child's learning style

matches the teaching approach, the better the 
child would learn. Researchers have identified over 20 styles of learning.

LOCUS OF CONTROL: LOCus of control is a personality construct referring to an individual's perception of the outcome or occurrence of events as determined primarily by internal focus, i.e., by his/her own behavior, as opposed to external forces such as fate or luck. In this study, it was measured by the Intellectual Achievement Responsibility Questionnaire (Crandall, Katkovsky, \& Crandall, 1965).

MATCHING STYLE: Matching style refers to the conscious effort on the part of the teacher to provide instruction in a manner that best matches the learning style of the child. Based on information about the children, the teacher alters his/her normal teaching practices to provide more appropriate instruction for a segment or the total class. STUDENT TEAMS-ACADEMIC Student teams-achievement divisions or STAD is DIVISIONS: a particular cooperative learning technique which fosters cooperation among students in the classroom for. STAD is made up of five interlocking components: class presentations, teams, quizzes, individual improvement scores, and team recognition. 


\section{Summary}

This chapter presented an introduction to the topic, the importance of, and impact of leaming styles on student achievement. Because learning styles approaches were usually implemented in individualized education, a whole group teaching strategy was sought which would meet the needs of the learning styles of the below average learner. The teaching strategy chosen was cooperative learning. Furthermore, it was decided to evaluate changes in spelling achievement, locus of control and self-concept of students exposed to this strategy.

The remainder of this dissertation is organized into the following chapters: Chapter 2 consists of a review of the literature relevant to the study. Chapter 3 describes the methodology including, the subjects of the study, and procedures used for collecting and analyzing the data. The research findings are reported in Chapter 4. Chapter 5 summarizes of the findings, presents conclusions, draws implications, and recommends further research. 


\section{Chapter Two}

\section{Review of the Literature}

Introduction

This chapter is divided into two major sections. The first section addresses the literature in the area of learning styles. In this portion of the review, the various types of learning styles and their interaction with teaching styles is presented. Included in this portion of the chapter is a discussion of locus of control as a learning style. The second section presents research on cooperative learning. The impact of cooperative learning on social growth and self-esteen, on academic skills, and on racial/ethnic issues are also discussed.

\section{Learming Styles}

\section{Conceptualization of Learning Styles}

The first portion of this review focused on the conceptualization of or ideation supporting learning styles. But, before examining this literature, it was necessary that the underlying purposes of this effort be reviewed. The primary purpose of the effort to identify and teach through learning styles was stated by Keefe (1982) who said,

Ultimately, education must come to grips with the different learning needs of the individual learner. These learning differences flow from variations in individual intelligence, drive, skills and accomplishment as well as personal and family predisposition and the cultural influences of the wider society... (Keefe, 1982, p.43)

The key to effective schooling, based on Keefe's (1982) conceptualization, was to first understand student learning styles. Then, the instructor would design instruction and materials that respond 
directly to the individual learning needs of each student. Identifying and categorizing students' learning styles appeared to direct most of the efforts in the research in the area of learning styles.

Th" earliest conceptualizations of styles in learning focused on cognitive styles. These styles were defined as stable, typical, and consistent ways that individuals selected and organized environmental data (Keogh, 1973). This area of research indicated that successful learners tended to use specific and more effective strategies when attempting to understand and solve certain types of problems (Gerber, 1983). But these early studies tended to be limited in their definition of style.

One of the first extensive models of learning styles was proposed by Canfield and Lafferty (1970). These authors brought forth a model which discussed conditions, content, modes, and expectations as crucial elements in learning styles. Dunn \& Dunn (1972) developed a completely different model. Their model contained eighteen characteristics covering issues of environmental, sociological and physical characteristics. This model was later expanded to include the earlier cognitive styles and new categories to cover hemispheric specialization (Dunn, Cavanaugh, Eberle and Zenhausern, 1982). But this model basically focused on the stimuli and the elements involved in identifying differing learning styles. These authors have encapsulated their ideas in a test, the Learning Style Indicator (LSI) (Dunn, Dunn \& Price, 1982), which identified the learning styles of students within a classroom.

A separate model was proposed by Gregorc (1979) who emphasized the distinctive behaviors in which students interacted with the environment 
as well as the bi-polar domains of random/sequential and concrete/ abstract. In a different approach, Letteri (1976) detailed a "cognitive profile" which was composed of seven cognitive areas noted for their impact upon academic achievement.

Responding to the apparent differences in children from Hispanic backgrounds, Ramirez and Castaneda (1974) identified a learning style that touched upon field dependence/independence, field sensitivity as well as the differences due to cultural backgrounds. Comparatively, Schmeck (Schmeck, Ribich and Ramanaiah, 1977) had been pursuing a learning style model that was aimed at assessing the learning behavior and conceptual activities of the learner.

In summary, a number of models of student learning styles were developed since the late 1960's. Each of these models had its proponents, advocates and detractors. But before one could draw conclusions about their efficacy, one needed to examine the impact of learning styles on student performance. The next section reviews these models in terms of student achievement.

Models of Learning Styles. One of the major issues facing research on learning styles has been the problem of a clear definition of what constituted a learning style. Currently, there have been a wide number of definitions and approaches to the area of leaming styles. As suggested by Cornett (1983), learning styles were defined as consistent learning patterns which have a certain amount of variability across individuals. The idea that learning styles were consistent but with individual variance was also supported by Guild and Granger (1985). 
Guild and Granger (1985) also indicated that there were three primary ways that styles could be conceptualized. These styles were: cognitive, affective, and behavioral/perceptual. These authors felt three major categories summarized the extensive number of models in the area of learning styles in a manner that best organized them. These categories are explained in more detail below.

Cognitive Models. The idea that individuals used different styles in learning or in using their cognitive abilities has pervaded psychology and education for over half a century. Gordon w. Allport (1931, 1961) described such styles in his early work in the 1930's. According to Allport (1961), the idea of style, as a view of individual differences in learning, appeared to coexist with the development of the study of personality.

The studies of cognitive styles were often contained in the early works on perception and cognition. Exemplary of the works during the 1940's and early 1950's, Klein (1951) felt that an individual "continually brings to bear in any kind of situation what for him are 'preferred' ways of meeting reality" (p. 336). These works, during these times, were heavily colored by the existing views of education and lacking clarity because the idea of cognitive style was not as clearly identified as it is today.

Due to these factors, Klein (1951) referred to individuals' cognitive styles in terms of levelers or sharpeners. Levelers were individuals who appeared to be less assertive, less confrontive and easily manipulated. Sharpeners were their direct opposites, i.e., liked competition and confrontation, were highly motivated to attain, and were 
very success oriented. As was apparent from these ideas, cognitive style was embedded with personality constructs, and the two models at this time had not been separated.

One individual who had identified cognitive style during this time was Herman A. Witkin. In a series of experiments dating from World War II, Witkin (Witkin, 1976; Witkin, Moore, Goodenough, and Cox, 1977) had identified two distinct cognitive styles, field independence and field dependence. Basing his experiments on the performances of pilots during the Second World War, it became obvious that two distinct approaches were being demonstrated by them. For the field independent, the individual's choices were less affected by the surrounding information or situation (the field) than were the field dependent.

Though field dependence-independence appeared to be a factor that influenced the educational performance of ethnically different children (Witkin, et. al., 1977), other studies have indicated that field dependence-independence continued to separate ethnic groups but did not clearly account for many differences in the children. The work of Kagan, Zahn, \& Gealy (1977) indicated that the greater field dependence of Mexican-American children was not correlated with their tendency to choose more cooperative alternatives in game situations.

Similarly, Hoppe, Kagan and Zahn (1977) showed that the less competitiveness of Mexican-Americans in mother-child conflict resolution was not related to field dependence-independence. However, most recently, Kagan (1984) has concluded that field dependence-independence describes only a limited portion of the educational performance of the ethnically different child. He concluded that no single construct like 
field dependence-independence could explain the various differences culturally and educationally.

One of the more current areas of interest in cognitive styles has been in brain functions and the specializations by the brain hemispheres (Cornett, 1983). This author believed that much of a person's cognitive learning style could be related to the functioning of the hemispheres. Dunn, Cavanaugh, Eberle and Zenhausern (1982) expressed this same position and advocated that teachers make the necessary adjustments to the classroom to adjust the classroom environment appropriately for the different learning styles.

Likewise, Gregorc (1982) has spoken of different mind qualities. In his description, he emphasized how we took in and how we processed information, the ways we decoded, encoded, processed, stored and retrieved information. Following a similar path, Dunn and Dumn (1975a) have investigated a wide range of learning preferences that reflect cognitive styles. Such views of the cognitive functioning and styles of students have begun to intrigue teachers and administrators. As a result, researchers have started to expand into the areas of teaching style, curriculum, and the cognitive styles of the learner.

Affective Models. One of the earliest affective models was developed by C. G. Jung (1971). Jung felt that, while people operated in a wide range of different situations, they would develop a series of confortable patterns. These comfortable patterns would lead to predictable ways, or "types" or styles of personality. Jung believed that individuals developed across four major categories: sensing, intuiting, thinking and feeling. 
While these major categories would control much of the personal affective style, each could be expressed differently depending on the other major variable, the style of expressing an emotion, extraversion and its corollary, introversion. The four major functions combined with the two styles of expression provided the basis of Jung's descriptions of the behavior of humans. Jung felt that each of us was born with a proclivity for a particular pattern and that change, while possible, would be a slow process due to these proclivities (Guild and Garger, 1985),

Jung's ideas were put into practical use by Myers (1962, 1980) and Briggs (Myers \& Briggs, 1976). In addition to the four functions identified by Jung, Myers and Briggs believed that there were two other important functions, judging and perceiving. Myers and Briggs extended Jung's conceptualizations to include these six functions and two ways of expressing into a set of four opposites: sensing- intuiting, thinking-feeling, extraversion-introversion, and judging- perceiving.

A number of authors have devised approaches to education reflecting this ideation. Most of these systems addressed the effect of communication styles on the affect of the child. The work of Mok (1974) and Simon and Byram (1977) identified the importance of these communication patterns in the interaction of teachers, students, parents and administrators. But, as Guild and Garger (1985) pointed out, it was the awareness of and willingness to "style-flex" that had one of the greatest impacts of the style research. As Hunt (1980) said, "The best teaching approach in a situation cannot be specified in advance since its central feature lies in its flexibility" (p. 288). 
Another area of affective styles was that of locus of control, a paradigm contained under the rubric of attribution theory. The ideation of locus of control stemmed from Rotter's (1966) social learning theory which was added to by Weiner $(1972,1974)$. According to these theorists, the individual accounts for their success or lack of success, say in academic performance, by developing an explanation in which either the causation was seen to reside outside the individual (externals) or within the individual (internals). The internal versus external dimension of behavior was known as the locus of control orientation (Autry and Langenbach, 1985).

Weiner's (1972) formulation of locus of control was focused on the causal explanations people give for their successes and failures and how those explanations affect subsequent expectancies and behavior. The individual's explanation for a given outcome was seen as being attributed to a combination of four causal elements: ability, effort, task difficulty, and luck. Ability and effort were identified as internal qualities, while task difficulty and luck were signs of external characterizations. All four could be influenced by other cognitions, and the perception that one's progress was prevented by circumstances beyond one's control could account for a number of behavior deficits (Carver \& Scheier, 1981).

In other words, this type of affective style had been noted as having an impact on the performance of the individual and being capable of predicting future behavior. In fact, according to the statements of Covington and Omelich (1984), locus of control had been shown to have a consistent, positive relationship with academic achievement. Overall, 
the area of locus of control contained an important type of learning style and one that has been extensively researched in the past fifteen years.

Behavioral/Perceptual. The body of research constituting the area of behavioral/ perceptual learning styles would be identified as "learning styles" by most teachers. This area contained those styles that were termed modalities, such as, visual, auditory, kinesthetic and tactile. Barbe and Swassing (1979) defined modalities as "any of the sensory channels through which an individual receives and retains information. ...[S]ensation, perception, and memory constitute what we are calling modalities" (p. 1). And, as Cornett (1983) indicated, the major modalities were the most important sensory channels for education.

The work completed by Dumn and Dunn $(1972,1978)$ has been frequently associated with modalities. Their work led them to develop a test for learning styles (Dunn, Dunn \& Price, 1979) which originally evaluated eighteen learning styles and has been updated to include twenty four styles (Price, Dunn \& Dunn, 1977). Their model has expanded to include cognitive style, and left and right brain style or hemispheric preferences, which were incorporated as simultaneous and successive processing (Dunn, 1984). Learning Styles and Student Performance

Research on students and learning styles had indicated that adjusting the teaching approach to the student learning style resulted in improvements in academic performance. This research could be categorized into those works done with gifted children and that completed with non-gifted children. 
In terms of the gifted learner, styles often discriminate between gifted and non-gifted. The study of gifted and non-gifted students by Kaley (1977) found that learning style was a statistically stronger and more reliable predictor of reading achievement than was an IQ score. Likewise, Hudes, Saladino and Miegler (1977) discovered strong relationships between giftedness and self-concept. They demonstrated that gifted students with high self-concept were significantly more persistent, more responsible and needed less mobility than did low self-concept gifted students.

More recently, Dunn and Price (1980) researched the styles of the gifted more extensively and found that gifted children preferred low structure, flexibility in learning, formal design of the learning paradigm, were highly persistent, but were low in responsibility or in conformity. However, as Griggs (1981) had reported, there were wide differences as well as similarities in gifted children in terms of their learning styles.

The literature reviewed for the gifted child (Dunn and Price, 1980) showed that there were strong preferences being tapped in terms of the learning style of the gifted child. Similarly, the literature dealing with the non-gifted, typical child not only shows learning style preferences but also had reflected the fact that matching the students' style of learning impacts academic outcomes. The literature of the wide range of learning styles in one classroom dates, originally, from the work of Copenhaven (1979) who demonstrated that many different styles were present in the typical classroom and that such differences were difficult to logistically handle for the teacher. 
Children with special needs, i.e., a learning disabled child or below average student, have also been shown to have very strong preferences. In one study by Wingo (1980), low or poor reading children were less motivated, needed more structure, and preferred learning with an adult. In another study of 85 school aged children in grades 3 through 8, Price, Dunn and Sanders (1981) indicated that poor readers needed mobility, needed to be adult motivated, were lower in persistence and in nonconformity. And, as summarized by Dumn and Dunn (1979), this group of learners had been shown to have a tactual preference.

However, learning styles have been shown to be not necessarily predictive of academic failure. Barbe and Milone (1981) believed that kinesthetic learners (usually seen predominantly in special education classrooms) would be poor learners in all academic settings. However, in reviewing the academic performance of identified kinesthetic learners, these authors showed that the kinesthetic learners were achieving equally to other learners in the regular classroom. These authors also added that many kinesthetic learners turn out to be very good students, e. g., surgeons, dentists, etc. In fact, Rhodes scholars were frequently kinesthetic learners.

In related literature, identifying a learner's style did not necessarily identify their reading ability. As McCammon (1981) pointed out, students with strong visual preferences were more likely to be poor readers than good ones. In summary, wide preferences in learning styles have been shown to exist for both gifted, learning disabled and average students. But, one question still remained. What was the impact of learning styles upon academic performance in the classroom? 
Matching Learning Style and Teaching Methodology

The review of literature to this point has illustrated the fact that there are specific learning styles and that these learning styles impacted students. But, as stated before, it was necessary to elucidate the relative importance of student learning style in the classroom. One study which addressed this topic was completed by Trautman (1979) who researched the impact of instructing students with either global or analytical learning styles in either a global or analytical instructional style.

Using social studies as a curriculum, Trautman (1979) illustrated the following: when there was a match between learning and teaching styles, the students increased their productivity, improved their attitudes toward learning, and had a greater sense of their ability to complete their studies. In a similar study, Cafferty (1980) examined the impact of matching learning and teaching styles on student grade point average. As expected, students whose style most closely matched that of the teacher achieved higher grade point averages.

Carbo (1980), in a study of matching reading instruction with learning style, found that when a phonetic approach was used with students who learned auditorily, they learned to read. And when a global approach was used with students who learned visually, they learned. This author indicated that the key was the match between the demands of the learning experience and the individual's learning strengths.

More recently, Shea (1983) studied the impact of matching and mismatching styles upon the academic performance of ninth graders. The results of this study showed significant positive outcomes in terms of 
the reading achievement for students with high congruence between learning and teaching styles.

In a similar matching and mismatching learning styles study, Virostko (1983) examined the impact of the time of day preferences on individual achievement and school attendance. Using an elementary school age group, children's learning styles for time of day preferences were matched and then mismatched over a two year period. The results of this investigation pointed out the children whose time preferences were congmuent with their class schedules achieved significantly higher mathematics and reading achievement test scores.

In summary, this review of the literature has demonstrated that, when learning style was matched with teaching style, the children had higher achievement. But these efforts to date have not provided close examinations of the alterations that occur in groups of low-achieving students. Since low-achieving students continue to make up a large portion of every class and constitute large proportions at some school sites, examination of the impact of matching teaching and student learning styles for this group represents significant information.

\section{Impact on Alternate Areas}

Most research on learning styles had focused on its impact upon academic attainment (Carbo, 1980; Shea, 1983; Virostko, 1983) and upon school attendance. Though these areas were important, various authors would argue that one must consider more than academic attainment. For example, Laosa (1977) and Buriel (1978) have argued that one must 
consider the child's "cognitive style" when examining the outcomes for various sub-groups.

Furthermore, Griggs and Price (1981) evaluated the interaction of self-concept and learning styles on junior high school children. They indicated that high and low self-concept students differed significantly in terms of their persistence in school. The high and low self-concept students were also different in their responsibility.

In the same vein, Cornett (1983) summarized a number of learning style studies. This author concluded that teaching, which was adjusted for the students' learning styles, had shown good impact of affective components. Overall, these results and recommendations have demonstrated that teaching through the students' learning styles had impact on other areas beside academic performance.

\section{Cooperative Learning Model}

The model used in this study is based on the theory of cooperative goal structuring. A cooperative goal structure was defined by Kelley and Thibaut (1969) as one in which the individual's rewards are directly proportional to the quality of the group work. Conversely, a competitive structure was defined as one in which individuals are rewarded so that one would receive a maximun reward and the less successful competitors lesser or no rewards.

In the educational setting, cooperative structures have been identified as having the following common elements: a) students work together in structured teams to accomplish a task; b) each student on the team is offered the opportunity to contribute to the team's overall 
success; and c) each student on the team is individually accountable for learming the academic materials (Hollifield and Slavin, 1980).

The basic assumption underlying the cooperative learning model was that interactions were crucial to the mastery of many academic skills. Traditionally, researchers have focused most extensively on the student-teacher interaction or on the student-curriculum interaction. But more recently, interest has developed in student-student interactions (Carlin and Sund, 1971; Johnson, 1975a; and, Johnson and Ahlgren, 1976).

This research had shown important outcomes at its outset. For example, Carlin and Sund (1971) found that meaningful student-student interaction

"tends to produce more sustained variety and enriched responses both from individuals and from a greater variety of children, contributes to more group cooperation, and approaches a more realistic social situation (p.39)."

Further, Weigel, Wiser and Cook (1975) noted improved cross-racial attitudes when cooperative learning models were used in classrooms. Types of Cooperative Learning Classroom Models

There were several cooperative learning models that have been used within the classroom (Sharan, 1980). Northcutt and Watson (1986) divided these models into simple and complex structures. The simple models cited were: group discussion; numbered heads together; team practice and drill; peer tutoring; team grades; bootstrap, a grade weighting paradigm; team products; roundtable, a strategy of one student completing only a portion of the assignment; and, cooperative review. 
The complex models addressed by Northcutt and Watson (1986) were: Student Teams - Achievement Divisions (STAD); Teams-Games-Tournaments (TGT); Jigsaw; and, Jigsaw II. These were termed complex structures due to the fact that use of such models within the classroom demanded that the teacher make extensive preparations for implementation and maintenance of the structures. Slavin (1980b) stated that these complex models have been the most widely researched and evaluated.

Student team-achievement divisions (STAD). This method was useful in grades 2-12 for any material in which questions with one right answer can be posed. The teacher presented a lesson, after which students studied worksheets in a 4- to 5-member, heterogeneous teams. Students then took individual quizzes, and team scores were computed by the degree to which each student improved over his or her own previous record (Slavin, 1978, 1983).

Teams-games-tournaments (TGT). Like STAD, TGT was also useful in grades 2-12 for any material in which questions with one correct answer can be posed. However, TGT replaced quizzes and improvement scores with a system of academic games and tournaments. Learning teams were divided so that students from each team compete with other students who have similar levels of past performance. Once a game or tournament was held, the score of the individual was added to the team's score to bring recognition and reward to the team (DeVries and Slavin, 1978; Slavin, 1983).

Jigsaw I and II. These cooperative learning strategies were judged to be most useful for the mastery of English, social studies, and other subjects in which a subject could be divided into discrete areas of 
expertise. These two versions of a similar method use the principle of individual students becoming experts on particular sections of a lesson which they then teach to their fellow teammates. Since any classroom consisted of several teans whose work was divided into identical jigsaw pieces, students with the same material to learn could begin by studying together. Students received either individual grades or team scores based on quizzes (Aronson, et. al., 1978; Slavin, 1980, 1983).

Team-assisted Individualization (TAI). Slavin (1985) has added one more technique to the general set of systematized approaches of cooperative learning. TAI combined the use of cooperative teams with individualized instruction in the area of elementary mathematics. Students worked in a 4- to 5-member heterogeneous teams with self-instructional materials at their own levels and rates.

The students themselves (Slavin, 1985) took responsibility for all checking, management, and routing, and helped one another with problems, freeing the teacher to spend most of his or her time instructing small groups of students (drawn from the various teams). These small groups would be working on similar concepts as the teams. Teams were rewarded with certificates if they attained preset standards in terms of the number of units mastered by all team members each week. Outcomes of Cooperative Learning Strategies

The effects of cooperative learning have been examined in its impact on ethnic interactions, academic skills and prosocial development across students. The first section of this review addresses the ethnic outcomes, the second, the academic outcomes, and the last, prosocial changes attributed to the use of cooperative learning strategies. 
Impact on ethnic interactions. Despite the mandates to integrate the public schools that have been in effect over the past 30 years, the promise of school desegregation and integration for improving racial relationships have been largely unfulfilled (Gerard and Miller, 1975; Hansell and Slavin, 1981; Stephan, 1978). Furthermore, as Weinberg (1983) concluded, integration, improved race relations and excellence in education were inexorably interconnected.

Interracial friendships. Because of the general failure of integration to bring about changes in ethnic relationships, researchers have been seeking educational practices that do improve race relations. As one part of this effort, Slavin and Madden (1979) analyzed a number of school practices at the high school level for their impact on enhancing racial interactions. These authors, in reviewing the responses of students on racial perceptions and interactions, determined that specifically structured relationships between minority and majority students via cooperative learning experiences had the most consistent effect on interracial attitudes and behaviors. These authors felt that cooperative learning structures were more efficacious than class discussions of race relations, minority history classes, teacher workshops on relationships between races, and biracial advisory committees.

The bases for their conclusions were a number of studies examining cooperative learning approaches and race relations. These studies indicated that when black and white students were assigned to multi-ethnic learning teams and were afforded equal-status interaction, they increased their number of cross-race friendships when compared with 
students in traditional classes (Aronson, Blaney, Sikes, Stephan, \& Snapp, 1975; De Vries, Edwards, \& Slavin, 1978; Johnson \& Johnson, 1978). Slavin (1979) followed these intergroup friendships over a number of months following the completion of his study. Students, who had been in cooperative learning classes, were still able to name significantly more friends outside their own ethnic groups than did students who had been in control classes.

Pursuing the idea that structured, cooperative learning settings demonstrated the greatest impact on cross-racial attitudes, slavin and Oickle (1980) examined changes in cross-race friendships due to STAD. Significant gains in white friendships toward blacks as a result of a STAD cooperative learning experience were denoted in this study. Despite the gains in white friendships, however, no significant difference was found in black friendships toward whites.

Hansell and Slavin (1981) studied cross-race friendships between black and white students using a STAD cooperative learning structure. Participation in cooperative teams resulted in increased reciprocated cross-race friendship choices which were termed "strong interracial friendships" (p. 99). Concurrently, these strong cross-race friendship choices were not only made and received equally among blacks and whites, but they were distributed evenly across sex and achievement levels. More recently, Kagan, Zahn, Widaman, Schwarzwald and Tyrell (1985) found that STAD (and TGT) reversed a trend toward ethnic polarization of friendship choices among Anglo, Hispanic, and Black students within the United States. Sharan, Kussel, Hertz-Lazarowitz, Bejarano, Raviv, and Sharan (1984) also noted positive effects of STAD on ethnic attitudes of 
both Middle Eastern and European Jews in Israeli schools. In summary, then, cooperative teaching techniques, in general, and STAD, in particular, have shown themselves to be effective approaches for improving cross-racial friendships among a number of different ethnic groups.

Impact on academic achievement. Specific cooperative techniques, such as STAD and TGT have shown to have more positive effects on academic achievement than less structured techniques (Slavin, 1980a). Slavin attributed this effect to the highly structured system of instruction, tean tasks, and team rewards evident in STAD as compared to other cooperative approaches which appeared to be lower in structure and in individual responsibility for learning. Moreover, Johnson, Maruyama, Johnson, Nelson, \& Skon (1981) concluded that there was considerable evidence that cooperative learning approaches were significantly superior to competitive or individualistic teaching strategies, in terms of academic achievement.

Exemplary were the studies of Lucker, Rosenfeld, Sikes, \& Aronson (1974), Slavin (1977), and Slavin and Oickle (1981). In general, these studies showed substantial improvement in the performance of typical, minority students, although White students also achieved more as an outcome of cooperative learning. In the Slavin (1977) and Slavin and Oickle (1981) studies, control whites had higher achievement than control Blacks on the pre- and posttests, but the significant differences initially between the two racial groups became insignificant by the end of the study. 
In a second meta-analysis of cooperative learning, Johnson, Johnson, \& Maruyama (1983) concluded that these techniques did result in higher academic achievement for the participants. However, as reported by Talmage, Pascarella, and Ford (1984), academic achievement was improved in the area of reading but not in language arts. This study, which was conducted over a three year period, did not implement one specific, cooperative techniques, such as STAD or TGT. Instead, the teachers were given appropriate training in cooperative goal structuring techniques.

The results of this project were not as supportive as those cited by Yager (1986) who used both STAD and TGT approaches to learming with third grade students. Yager (1986) implemented these approaches over a three month period. At the end of the time period, students in the two cooperative groups outperformed the students in an individualized, training group. Furthermore, when the students were tested at a three month follow up, the students in the cooperative learning groups demonstrated superior recall to those students in the individualized groups. Likewise, Hernandez and Descamps (1986), in a review of approaches that assisted Hispanics in learning in schools, concluded that cooperative leaming techniques had significant impact on the academic skills of Hispanic youth who were average students.

In summary, the works of Johnson, et. al. (1981), Johnson, Johnson, \& Maruyama (1983), Kagan (1983), Slavin (1985) and Hernandez and Descamps (1986) have supported the fact that cooperative learning was a more effective approach to the education of minority youth. In fact, a number of the studies specifically compared White and Black academic 
mastery, or the academic achievement of typical Hispanics with other racial groups (Kagan, 1983). Overall, cooperative techniques have been shown to be more effective, in terms of academic achievement for these youth, than were traditional approaches.

Impact on Self-Esteem. In their meta-analysis, Johnson, Johnson, \& Maruyama (1983) stated that there was strong evidence that cooperative techniques resulted in increased self-esteem as well as healthier processes for assessing self-worth. In fact, cooperation and self-esteem appeared to be tied together (Norem-Hebersein \& Johnson, 1981). These authors noted that attitudes toward cooperation tended to be related to basic self-acceptance and positive self-evaluation compared to peers. Competitiveness, on the other hand, appeared to be more strongly related to conditional self-acceptance; whereas, positive attitudes toward individualistic situations tended to be related to basic self-rejection. More specifically, Ames (1981) stated that winning in a competitive situation appeared to produce feelings of self-aggrandizement. Losing in competitive situations tended to lower students' self-perceptions of their ability and satisfaction with the situation. Furthermore, Ames (1981) and Ames and Felker (1977) pointed out that failure in competitive situations promoted increased self-derogation.

Slavin, Leavy, \& Madden (1984) believed that these differences were partly a result of the student being more successful in school when working in teams, and partly a result of the student feeling more liked by others due to the cooperative learning structure. Cooperatively grouped students generally supported their peers' academic success to a higher level than do traditionally taught students, which improved the 
general climate of the school and classroom. Students, working in cooperative groups, felt greater control over their own (academic) fate, showed more concern for others, and were more likely to express greater liking for school (Slavin, 1985).

Summarizing, these studies appeared to indicate that cooperative techniques would offer positive experiences for students who were experiencing them. Yet, despite this good base of studies, there has been very limited examination of the changes in self-esteem of the below average student in the cooperative classroom. This present study examined the effect of cooperative learning on this irmportant group of students.

\section{Summary}

This chapter has reviewed the literature for the areas of learning styles and of cooperative learning. Studies of learning styles conclude that matching teaching style to learning style appeared to result in improved academics for the students and offered a technique for addressing the needs of the atypical learner. But, due to the emphasis on individualized instruction, it was felt that the average teacher could not implement this approach effectively.

As a result, cooperative learning was explored as a teaching technique that would generally approximate the preferred learning styles of the below average student and could be implemented on a large group basis. Review of the literature for cooperative learning indicated that cooperative techniques have been shown to be effective for improving cross-racial friendships, for improving academic achievement, and for 
improving self-esteem among groups of typical students, and appeared to be one approach that could impact one's locus of control.

To determine if cooperative learning was effective with the below average student, this study examined changes in their spelling achievement, self-esteem and locus of control. The next chapter presents the methodology for this study including research design, statistical analyses and limitations. 
CHAPTER THREE

Research Design and Methodology

\section{Introduction}

This study attempted to determine if the use of a teaching strategy (cocperative learning) which more closely matched the learning styles of below average students would result in significant changes in spelling achievement, in self-concept and in locus of control of these students. As a result, a specific research design and methodology were identified to assist in the determination of the impact of the teaching strategy. This chapter discusses the sites, the setting, the subjects, the procedure, the study's instrumentation and data analysis.

\section{Sites}

The sites for this study were two public elementary schools (grades $\mathrm{K}-6)$ located in a large urban city in the Southwest. The first school's population was drawn from middle to lower socioeconomic class urban environments, with $50 \%$ of the parents employed at semiskilled or skilled jobs as reported in the socioeconomic status report, from the California Assessment Program, Table C (State of California, 1985). In addition, 27.5\% of the parents received Aid to Families with Dependent Children, another indicator of the socioeconomic conditions at this school. The school's socioeconomic index of 1.82 , according to the California Assessment Program norms (1985), was higher than 31 percent of the schools in the state.

The first site drew $75 \%$ of its students from its immediate neighborhood. In addition, $25 \%$ of its student body attended as part of 
its designation as a magnet school. As a magnet school, this site offered specialized programs and courses for the children in mathematics and science, counseling, and media production. Though other school sites might offer similar programs, magnet schools were provided more economic support and careful selection of teachers to provide the specialized programs.

The second site was a school in the same district which drew from a similar population. Its socioeconomic index of 1.80 (CAP, 1985) was higher than 29 percent of schools in the state. Nearly $85 \%$ of the parents at this site did semiskilled or skilled work. Furthermore, $19.6 \%$ received Aid to Families with Dependent Children.

Students at both schools performed above district norms in written language achievement on the 1985 California Assessment Program Basic Skills tests (4/85) but within the range expected of a school with their backgrounds as designated by California Assessment Program data. A comparison of the percentage of third grade students in each quarter of the state's student distribution showed similarities between the two school sites (see Table 1).

When last year's third grade students were asked to indicate how they felt about written language, their responses were divided into three categories as seen in Table 2. As noted in this table, $78 \%$ of the students at Site 2 and $80 \%$ of the students at Site One liked written language "a little" or "very much". 
Table 1

Percentages of Students Working at the Four Quartiles on the California

Achievement Program Basic Skills Test Written Language Subtest at the

Two School Sites

\begin{tabular}{|c|c|c|c|c|c|c|}
\hline & & te or & & & te Tr & \\
\hline & '83 & $' 84$ & $' 85$ & $' 83$ & $\cdot 84$ & $' 85$ \\
\hline Q1 - Under 25\% & $25 \%$ & $28 \%$ & $24 \%$ & $28 \%$ & $23 \%$ & $14 \%$ \\
\hline Q2 - Between 25 and 50\% & $30 \%$ & $27 \%$ & $26 \%$ & $29 \%$ & $27 \%$ & $26 \%$ \\
\hline 3 - Between 50 and $75 \%$ & $28 \%$ & $27 \%$ & $27 \%$ & $23 \%$ & $27 \%$ & $20 \%$ \\
\hline 4 - Over $75 \%$ & $17 \%$ & $18 \%$ & $23 \%$ & $20 \%$ & $23 \%$ & $40 \%$ \\
\hline
\end{tabular}

Table 2

Percentages of Third Grade Students Who Expressed Various Attitudes

of Liking Written Language at the Two Sites

$\begin{array}{lcc} & \text { Site One } & \text { Site Two } \\ \text { Very Much } & 32 \% & 46 \% \\ \text { A Little } & 48 \% & 32 \% \\ \text { Not at All } & 20 \% & 22 \%\end{array}$

\section{The Setting}

The setting for this study was the regular, self-contained classroom of the participating teachers. The teachers of the experimental group were responsible for using cooperative learning with the students during 
the spelling lessons every day. There were three experimental and three control group teachers in this study. Two enperimental group teachers were teaching at site one as was one control group teacher. One experimental group teacher and two control group teachers were working at the school referred to as site two. The diagram, displayed as Table 3 , presents this arrangement graphically.

The children in the experimental group were completing the same spelling text as the control group. The number of lessons taught in the experimental and control group classrooms were monitored to insure that both groups received nearly equal amounts of instructional time and lessons completed in spelling.

Table 3

Diagram of the Number of Teachers by Experimental and Control Groups at Each Site

Number of Teachers and Students per Site First Site $\quad$ Second Site

Experimental

Teachers (Students)

Control

Teachers (Students)

$1(14)$

$2(40)$

Totals

$3(49)$

$3(53)$ 


\section{Subjects}

The total population of grade 3 at the first site numbered 91 students. The experimental students who participated in the study numbered 35 while the control group students numbered 14. At the second site, there were 89 third grade students. Of these, 13 students were in the experimental while 40 students were in the two control group classrooms. The breakdown of groups by sex appears in Table 4. As seen in this table, there were 15 males in the experimental group from Site One. Of these 15, seven were non-white. There were eight males in the control group at Site one. Of these eight, two were non-white. At the second site, there were eight males who were in the experimental group, three of whom were non-white. Also, the second site contained 19 control students who were males, five of whom were non-white.

The experimental population within the two groups was not the total student population in these classrooms but only those individuals who scored below the 50th percentile on their Total Battery Score on the Comprehensive Test of Basic Skills. This test was administered in April, 1985 and these scores were used to identify the potential participants.

\section{Curriculum Design}

The experimental classes were taught in a cooperative way over a six week period using the district designated spelling text. The teachers of the control group also used this text and all of the teachers (experimental and control) were responsible for teaching spelling to their own classes. Teachers of the experimental and control groups were told to spend 20 minutes per day on spelling to insure that both groups of children received similar amounts of time in instruction. 
Table 4

Distributions of the Experimental and Control Groups at the

Two Sites by Gender of the Students

\begin{tabular}{llrr} 
& & First Site* & Second Site* \\
\cline { 3 - 4 } Boys & Experimental & $15(7)$ & $8(3)$ \\
& Control & $8(2)$ & $19(5)$ \\
Girls & Experimental & $20(4)$ & $5(2)$ \\
& Control & $6(3)$ & $21(7)$
\end{tabular}

* Numbers in parentheses indicate numbers of non-white students in each classroom.

The researcher, in order to insure that the curriculum was implemented appropriately, carried out a series of activities to become knowledgeable in cooperative learning. At the onset of this study, the researcher contacted Drs. Hugh "Bud" Mehan and Esteban Diaz from U.C.S.D. to identify appropriate interventions with atypical learners. These sources suggested contacts with $\mathrm{Dr}$. James Banks at the University of Washington as well as with Dr. Steve Isaacs, Director of Research, San Diego City Schools. Phone contacts were made with these individuals, who, in turn, recommended working with $\mathrm{Dr}$. Ron Hockwalt, Superintendent of Cajon Valley Elementary School District. After interviewing Dr. Hockwalt, he directed the researcher to specific articles on learning style and cooperative learning that were obtained at the library at San Diego State University's Love library. 
Additionally, phone contacts were made with Dr. Norm Gold, who works for the Office of Bilingual Education, and Maria Ortiz, who works for the Teacher Credentialing Office, State Department of Education. These individuals recommended contacts with Dr. Barbara Merino, Department of Education, U.C. Davis, and with Dr. Spencer Kagan, Department of Education, U.C. Riverside. A phone contact was made with both Dr. Merino and Dr. Kagan, while Dr. Kagan was additionally interviewed, while working in San Diego.

Dr. Kagan, who is considered to be one of the recognized experts in cooperative learning, recommended site visits to schools in Vista, California. Contact was made with Ken Miel, a dean of students within Vista, and a visitation was made at Olive School, Vista, to see the cooperative learning program in action. In addition, materials from the other cooperative learning programs operating in Fresno Unified School District and Irvine Unified School District were obtained.

While researching information on learning styles, the researcher made contact with Drs. Ken and Rita Dunn at St. John's University. These two individuals created the Learning Style Inventory. There was further interaction with Joann Ingraham, Executive Secretary, National Network on Learning Styles. Ms. Ingraham recommended working with Dr. Janet Perrin, an associate of the Dunn's. Finally, the researcher made contact with Dr. Gary Price, president of Price Systems, and a professor of Education, University of Kansas. These experiences provided the researcher with a strong background in how functioning programs operated and how to judge if teachers were, in fact, implementing cooperative learning programs appropriately. 
With this background, the researcher organized a meeting with the experimental group teachers. Every Tuesday during conference time (2:00-3:00 pm), the experimental group teachers met with the researcher. These meetings were held to review the implementation of cooperative learning in their classroom by these teachers. This period of time was devoted to insure that the teachers were using cooperative learning during spelling and that any problems arising during this implementation were dealt with as quickly as possible.

Structuring Cooperative Learning: The 1980 Handbook, developed by Virginia Lyons at the University of Minnesota (1980), was used to provide an outline to be followed. This source provided a general lesson plan that was built to accommodate the teaching of the spelling words. The lessons covered the instructional and subject matter objectives, explaining the process, monitoring, intervening to teach skills and teacher evaluation criteria. The control teachers did not receive any formal instruction on cooperative learning but followed the spelling curriculum prescribed by the district.

\section{Pilot Study}

From observations of below average students in the classroom by the experimenter, from reviewing extensive literature, and from comments by teachers, it appeared that the traditional teaching strategies were not working well with these atypical students. As a result, a pilot study of below average students was conducted using the Learning Style Inventory (LSI) to determine if there was a particular style that could best typify this group. The pilot study examined the performance on a sizeable group $(n=50)$ of below average students, who were in attendance 
at summer school, in order to identify common characteristics. These students met the definition of below average students due to the fact that they scored below the 50th percentile on the Comprehensive Test of Basic Skills and had been identified by their teachers as in need of remediation via summer school.

The children who were tested were drawn from a larger group of students who were participating in a summer school program for students scoring below the 50th percentile on the Comprehensive Test of Basic Skills. A group of third graders from the larger group took the Learning Style Indicator test. The test forms were sent to the scoring service offered by the Learning Styles Institute. The tests were scored, and individual and group profiles, expressed as standard scores, were returned.

The results were examined with emphasis placed on the performance of the group (since it was a summer school session, the individual scores could not be used to implement changes in teaching). The scores for the group were reported by the number of individuals either above a standard score of 60 (one standard deviation above the mean) or below 40 (one standard deviation below the mean). These below average students had five common characteristics:

1) The students were extremely low in their motivation by teachers or parent figures (no individuals scored above 60).

2) At the same time, the students scored relatively high in their peer orientation (only 10.9\% had scores above 60 on working alone and $30.9 \%$ had scores below 40 . Since $15 \%$ of scores typically occur one standard deviation above the mean and $15 \%$ 
occur one standard deviation below the mean (Isaacs and Michaels, 1983) having $30 \%$ below a standard score of 40 (one standard deviation) was double what would be expected.

3) The scores indicated that the students were extremely low in structure - suggesting that the students needed clear objectives not choices in how to approach the learning task (no individuals scored above 60).

4) Students also scored very high on having authority figures present to check assignments (29\% had scores above 60 . Again, $15 \%$ was the percent expected, based on a typical normal distribution (Isaacs and Michael, 1983), so this was double what would be expected).

5) Finally, it was noted that the students indicated that they needed to have assignments laid out for them, with assignments "do-able", and alternatives offered $(32.7 \%$ had scores above 60 , double what would be expected).

Summarizing these characteristics, the results seemed to suggest that the below average students demonstrate a strong preference for educational experiences which had a "group" or "social interaction" emphasis. They also preferred having authority figures present to check assignments, were relatively unmotivated by teachers and/or parents, were relatively motivated by peers and wanted to be successful in doing their assignments.

This pilot information related very well to the basic belief of this study that there was a general learning style of the slow-learner which might lead to improved instruction. The idea that there was a 
specific learning style for below average students was also clearly supported by the work of Cicourel and Mehan (1984). These authors indicated that: low performing children in the traditional classroom frequently need cooperative approaches versus competitive ones; and that the traditional teaching style of the teacher was often in conflict with the preferred learning styles of the students.

Cicourel and Mehan (1984) concluded that students needed to be in situations where greater interaction and cognitively appropriate demands could be met. This information lent support to the present study examining how a teaching style or methodology with greater interaction and appropriate cognitive demands would impact a group of below average students.

\section{Instrumentation}

Two standardized instruments and one criterion referenced instrument were administered on a pre- posttest basis to both the experimental and control groups. The two standardized instruments were the Piers-Harris Self Esteem Inventory and the Intellectual Achievement Responsibility Scale. A criterion referenced test evaluated the spelling ability of the students.

\section{Piers-Harris Self-Esteem Inventory. The Piers-Harris Self Esteem} Inventory (Piers and Harris, 1969) was an 80 item questionnaire designed for elementary aged children. This test required about 15-20 minutes for administration and was designed to tap the areas of self-confidence and self-esteem in children. It was developed primarily to study children's self-attitudes and the correlates of these attitudes. 
The Piers-Harris Inventory had been chosen to determine if there would be any noticeable change in the self-concept of the participating children as a function of experiencing cooperative learning, i.e., did the children feel better about themselves after being in a cooperative learning environment.

Reliability: The reliability of the Piers-Harris (Piers, 1969) had been established in several different manners. First using the Kuder-Richardson Formula 21, internal consistency coefficients emerged which ranged from .78 to .93 . More importantly, these coefficients were .90 and .93 for third graders.

Secondly, stability coefficients were determined by retesting children four months later. These coefficients ranged from .71 to .77 for third and fifth graders. Piers (1969) concluded that this scale had good internal consistency and adequate temporal stability.

Validity: The validity of this test (Piers, 1969) was demonstrated by a number of studies comparing the performance of this instrument with other recognized scales. Correlations between the Piers-Harris and other similar scales ranged from .31 to .68 , with a mean correlation of .60 . The results of these studies were discussed in the manual and the author concluded that validity had been substantially demonstrated.

Intellectual Achievement Responsibility Scale. The Intellectual Achievement Responsibility Scale (IAR) was developed by Crandall, Katkovsky and Crandall (1965) to determine if children could assume credit for the causation of both good and bad occurrences in their life. It also attempted to tap the general domain of personal responsibility for success in academic environments. 
The IAR is a 30 forced-choice item questionnaire. Each question stem described either a positive or negative achievement experience in children's daily lives. One portion of the stem implied that the causation of the problem was due to the child while the other portion placed the responsibility on someone outside the immediate environment. This scale was chosen to examine the changes in personal responsibility that might occur in a cooperative classroom environment. It was postulated that children would alter their view of personal responsibility due to the nature of the cooperative learning experience. Reliability: In the development of the instmment, the reliability was determined through several different procedures (Crandall, Katkovsky \& Crandall, 1965). Split-half reliabilities were determined for the odd/even items on the scale. These correlations ranged from 0.54 to 0.57 while a coefficient of 0.60 was generated by the Spearman-Brown Prophecy formula. The test-retest coefficients ranged from .66 to .74 over a two month testing interval. The authors indicated that these coefficients were moderately high.

Validity: The validity of the IAR was demonstrated by various studies by the Crandall, Katkovsky and Crandall (1965). For determination of its validity, checks were made with age and grade differences, with sex differences and by correlating the IAR with other similar measures. The validity checks for age, grade and sex all demonstrated appropriate statistical confirmation. Correlations with other measures ranged from 0.40 to 0.50 , and as high as 0.70 with measures of intellectual functioning. Since the correlation coefficients 
were relatively strong, the authors concluded that the validity of the IAR had been substantiated.

Criterion Referenced Instrument. The criterion referenced test was used in order to obtain better descriptive data on the classroom performance of the children. This criterion referenced test was developed by the author. For this test, every third word from the weekly spelling lists taken from the district spelling series was placed in a 40 word spelling test. This test was administered, as were the other instruments, in a pretest, posttest manner by the classroom teachers. The words chosen were drawn from the pool of words that both the experimental and control groups were taught during the period of this study.

\section{Procedures}

\section{Overview}

The following procedures were used in the study:

1) Identification of Teachers

2) The Training of Teachers

3) The Pretesting of Students

4) The Training of Students

5) Implementation Checks

6) The Posttesting of Students.

Identification of Teachers. The identification of the teachers for this study was completed over a two month period from January 1, 1986 through March, 1986. Two months were required for the researcher to identify potential sites, contact the school administrator, receive 
district approval and then make contact with teachers at the sites. Through this process, six teachers were identified to participate in this study. Three came from the staff at site one and three from the staff of site two. All six were willing to implement cooperative learning in their classrooms.

These teachers had been preliminarily screened by the researcher, considering their years of teaching experience and their education attainments. Their site administrators, when interviewed by the researcher, reported that the six teachers had relatively equal amounts and types of teaching experience, being teachers in their second through fourth years. Further, none of them had yet obtained a Master's degree. The site administrators also felt that these teachers were qualified teachers.

By random choice, two teachers were selected from the site one to receive training in cooperative teaching techniques first. The other teacher was promised training once the study was completed, but served as a control class during the study. Finally, it should be noted that there had been training in cooperative learning techniques at an earlier date at site one but the teachers participating in this study had not elected to attend that inservice opportunity.

One of the three teachers at site two was also randomly chosen to be trained in cooperative teaching techniques. The remaining two teachers had control classes. Since neither of these teachers had been exposed to any formal training in cooperative learning, these two control classes could be used to determine if the prior training at the first site influenced the control teacher at that site. 
Teacher Training. As an instructional leader and a principal, the experimenter identified the types of training materials and the amount of training necessary to develop the skills the experimental teachers needed to implement cooperative learning effectively. Next, the experimenter identified the resources available through the school district and arranged the release of the teachers for attendance at the presentations on cooperative learning. The experimenter also decided that the teachers would receive the best training through the use of a district inservice trainer.

The actual training of the experimental teachers about cooperative learning practices was conducted by the district inservice trainer, an individual who had been hired to conduct inservice and who had ten years experience as an inservice trainer of teachers. This individual was part of the inservice education effort in this large metropolitan school district and had conducted three years of training on cooperative learning prior to the onset of this effort. While the experimenter had the skills and ability to carry out this inservice, the major role of the researcher during the training was merely attendance at the training.

The use of an inservice-trainer helped increase the internal and external validity of this study for several reasons. First, the use of an individual who had extensive experience in training cooperative learning would result in better training for the participating teachers. Secondly, the use of this type of trainer would better represent the actual reality of inservice in a large school district of this type. Further, since this was a field experiment attempting to evaluate a 
"solution" to a problem, this type of trainer seemed to better match the model of the district for staff development.

Third, the use of an inservice-trainer obviated the possible impact of experimenter bias which might occur through the training. Since the experimenter would have some very focused expectations, these expectations could be easily transmitted through the training and the results could be suspect (Isaac and Michael, 1983). Therefore, the experimenter decided that the inservice-trainer appeared to be the best choice in this situation.

Training Sessions. The experimental teachers received eight hours of intensive inservice on cooperative learning. The training was divided into four sessions. The first session was an overview of cooperative learning. The second session involved observations in a classroom using cooperative learning.

The third inservice involved classroom demonstrations and a trial lesson was demonstrated by each teacher. The last was a review of the information and a check to insure the teachers had mastered the information. The training of the teachers in cooperative learning for the eight hours occurred over a two-week period beginning in the first week of April and concluding by the third week.

Once the training was completed, the experimental teachers began implementing cooperative learning in the classroom. To insure equal amounts of experience for the experimental students, the teachers completed a weekly time log on the use of the techniques. Upon examination of the $\log$, the experimental teachers were within 10 minutes of each other at the close of the experiment. 
Treatment. The treatment (cooperative learning) was evaluated during a specific curricular period (spelling) for a six week period beginning in mid-April and ending during the first week in June. Ideally, any curricular area chosen for such an effort should be one which all students experience and in which students could be heterogeneously grouped. Language arts, and spelling in particular, was one content area that all students experienced and for which students were already heterogeneously grouped. As a result, spelling was chosen.

This area, spelling, was used for several reasons. First, since spelling tests were given on a weekly basis in the classes, change in academic performance could be easily noted. Second, the teachers could more easily plan for this type of lesson. This was because spelling lessons tended to be more consistent in terms of time allotted to the subject than were mathematics and reading. Third, teachers have found it easier to plan for a cooperative spelling lesson because of the large group nature of such lessons. Fourth, the monitoring of the use of cooperative learning in spelling was also easier due to the specific allocated time and specific nature of the lessons.

Student Teams-Achievement Divisions (STAD) was the specific approach that was used. STAD was made up of five interlocking strategies (Slavin, 1980). These strategies were: class presentations, teams, quizzes, individual improvement scores and team recognition. STAD appeared to be an approach that could be quickly learned and implemented by the typical teacher. Because of its continuing reliance on class presentations, STAD was the cooperative learning strategy closest to the 
traditional classroom and, therefore, the most likely to be accepted by teachers.

During the treatment period, the experimental teachers created student teams in their classes. Each team was composed of four to six students. The members of the teams were selected so as to assure equal representation of boys and girls, of minority and majority students, and of lower, average, and higher achieving students on each team. Each team developed a name for their team and received recognition as a team.

Every week, the teacher made a presentation about the spelling assignment and the students took a test on the spelling words. Based on each student's performance on this test, the team was instructed to help the team members master the content of the lesson. Team members were given time to quiz each other and to complete spelling workbook exercises conjointly. On the second day of the week, students would begin completing the spelling exercises, working in groups.

On the third day, the time would be split between finishing the spelling exercises and begin quizzing each other on the spelling words. On the fourth day, the students would spend most of the time testing one another, in each of the teams. On the fifth day, the students again took the spelling test and recognition awards were given to teams demonstrating the greatest improvement from the spelling test at the beginning of the week (Slavin, 1980).

Testing of Students. 'The students' gender was identified as they were pretested on the IARS, on the Piers-Harris, and on the criterion referenced spelling test during the third and fourth weeks of April. The students were posttested during the second and third weeks of June. 
Training of Students. Students who were in the experimental group received six weeks of spelling instruction in which cooperative learning was the mode of instruction. This instruction began in the last week of April and concluded in the first week of June. Six weeks was the time recommended by the trainer of the experimental teachers. This length of time permitted evaluation of the impact of the strategy while not being overly demanding for the experimental teachers.

Implementation Checks. Both the experimental and control groups were visited by the experimenter once a week over the six week treatment period. For the experimental teacher, the experimenter asked if the teacher was having any difficulty with the implementation. If the teacher was experiencing any problems, the experimenter, with 10 years as an instructional leader, talked with the teacher in an attempt to resolve the problem. Most problems occurred at the beginning of implementation, and involved organizing the teams and the noise level in the classroom while the teans worked.

The control teachers were also visited by the experimenter. These contacts were made to counter-balance any impact the researcher (a principal) might have on the performance or efforts of the teachers. The general tone of these meetings was social and the experimenter focused on school issues during these meetings. The experimenter kept a log of his times and the general time for both groups was equal.

\section{Experimental Design}

The intact nonequivalent control group design was employed for the purposes of this study. This quasi-experimental design (Isaacs and 
Michaels, 1983) was recommended when the experimenter could not randomly assign subjects to treatments but must use naturally assembled groups.

The dependent variables were academic achievement, self-concept, and locus of control. The independent variables were exposure to cooperative learning and student gender. Due to the fact that two independent variables, cooperative experience and gender, were used, a factorial design was implemented in the statistical analysis.

\section{$\underline{\text { Statistical Analysis }}$}

The analysis of covariance was used as the statistical approach in this study because it allowed the comparison of posttest means after adjustment for any differences between the two groups with respect to pretest means. The analysis of covariance was the method preferred to compensate for any initial group differences between the experimental and control groups (Isaac and Michaels, 1983).

Since there were comparisons between the experimental and the control groups and for boys and girls, there were two independent variables, exposure to cooperative learning and gender. Further, comparisons between sites one and two were computed to determine if the prior training in cooperative learning appeared to influence the outcomes at the first site. The next section reviews the specific hypotheses and what rejection or acceptance of each null hypothesis would mean.

Hypothesis One

The first null hypothesis stated that there would be no significant difference shown in spelling achievement between the experimental group 
of below average students who experienced cooperative learning and the control group of below average students who did not. If the null hypothesis was rejected, it would indicate that the experimental group who participated in cooperative learning mastered more spelling words than did the control group. If the results failed to warrant a rejection of the null hypothesis, it would indicate that students taught using cooperative learning learned approximately equal numbers of words to those students who were taught in a traditional way.

Pre- and posttest scores of student responses on a criterion referenced spelling test were analyzed by experimental/control groups and by gender using a two-way analysis of covariance (ANCOVA) A 0.05 level of significance was used to evaluate statistical results. If the interaction of treatment and gender was significant, a test of simple main effects (Winer, 1962) was calculated to allow rejection of sub-hypotheses 1.1 and 1.2 (see p. 8). If the interaction was not significant, sub-hypotheses 1.1 and 1.2 would be accepted, indicating that experimental boys learned equal numbers of words as the control boys, and the experimental girls learned equal numbers of words as the control girls.

Hypothesis Two

The second null hypothesis stated that there would be no significant difference shown in self-concept between the experimental group of below average students who experienced cooperative learning and the control group of below average students who did not experience cooperative learning, as measured by the Piers-Harris Self-Concept Inventory. If the null hypothesis was rejected, it would indicate that 
the experimental group who participated in cooperative learning had different levels of self-concept than did the control group. If the results failed to warrant a rejection of the null hypothesis, it would indicate that students taught using cooperative learning had nearly equal levels of self-concept as those students who were taught in a traditional way.

Pre- and posttest scores of student responses on the Piers-Harris Self-Concept Inventory were analyzed by experimental/control groups and gender using a two-way analysis of covariance (ANCOVA). A significance level of 0.05 was used to evaluate statistical results. If the interaction of treatment and gender was significant, a test of simple main effects (Winer, 1962) was calculated to allow rejection of sub-hypotheses 2.1 and 2.2 (see $\mathrm{pp} .8-9$ ). If the interaction was not significant, sub-hypotheses 2.1 and 2.2 would be accepted, indicating that experimental boys had a level of self-concept equal to the control boys, and the experimental girls had a level of self-concept equal to the control girls. Hypothesis Three

The third null hypothesis stated that there would be no significant difference shown in locus of control between the experimental group of below average students who experienced cooperative learning and the control group of below average students who did not, as measured by the Intellectual Achievement Responsibility Questionnaire. If the null hypothesis is rejected, it would indicate that the experimental group who participated in cooperative learning had a different view of their locus of control than did the control group. If the results failed to 
warrant a rejection of the null hypothesis, it would indicate that students taught using cooperative learning had nearly the same view of their locus of control as those students who were taught in a traditional way.

Pre- and posttest scores of student responses on the Intellectual Achievement Responsibility questionnaire were analyzed by experimental/control groups and gender using a two-way analysis of covariance (ANCOVA). A 0.05 level of significance was used to evaluate statistical results. Since this was a two-way ANCOVA, differences between the genders were also indicated. If the interaction of treatment and gender was significant, a test of simple main effects (Winer, 1962) was calculated to allow rejection of sub-hypotheses 3.1 and 3.2 (see p. 9). If the interaction was not significant, sub-hypotheses 3.1 and 3.2 would be accepted, indicating that experimental boys had a similar locus of control to the control boys, and the experimental girls had a similar locus of control to the control girls.

\section{Limitations}

Using an intact nonequivalent control group design resulted in several threats to internal validity. When random assignment can not be employed, one can not be totally assured that the groups were equivalent. This study attempted to handle some of these sources of difference by having a control group and an experimental group at each of the sites. This step allowed some control over the effect that the different histories of the two sites might have on the outcomes.

Some of the limitations that affected this study are: 
1. The school sites were limited to one area of one school district and are applicable only to similar schools.

2. The effect of the training was limited to the area of spelling. Therefore, the results might be limited to this content area.

3. Interactions among teacher, method and the composition of the student group could limit the generalizability of this approach to similar classroom/school situations.

4. The selection of sites was limited by the willingness of the site administrator to allow the teachers to participate. This limitation could impact the application of the results to schools in which the site administrator was willing to have teachers try cooperative techniques.

5. The identification of students as slow-learners was limited by the fact that the last academic testing of the students had been in April, 1985, nearly one year prior to the research study. As a result, some of the students could be currently operating academically above this level and would limit the implications of this study to students who generally are below average students.

\section{Human Subjects Permission}

Since the students who were to participate in this study needed to be tested, parent permission for this testing was sought. This letter informed the parents that their child might be participating in different instruction for spelling. Their permission was sought for testing their child in order to evaluate a new instructional technique 
and that they had the right for their child to not participate in testing. This letter is reproduced in Appendix C.

\section{$\underline{\text { Summary }}$}

This chapter presented the research design and methodology. As part of that presentation, the qualities of the site and the setting were reviewed as were the qualities of the teachers and student participants. The pilot study that preceded the study was discussed as was the justification for the use of cooperative learning. Further, the curriculum design, the training procedures for the teachers, the reason for choosing spelling as the curricular area, the data collection procedures, and the instrumentation were described.

The statistical analyses, the analysis of covariance, was identified as the most appropriate statistical technique for analyzing pre- posttest data. In addition, the test of simple main effects was described as the correct statistical technique to use if there was a significant interaction. Finally, the limitations of the study were stated.

The next chapter presents a review of the purpose of the study with the statistical analyses of the three null hypotheses and analyses of the sub-hypotheses. These hypotheses are supported or rejected in the next chapter. Finally, a number of related analyses are presented in order to better understand the outcomes of the study. 


\section{CHAPTER FOUR}

Results

Introduction

This chapter is divided into four major sections. The first section restates the purpose of the study. The second addresses the analyses of the hypotheses. The third part presents related analyses which allow a better understanding of the data. The last section is a summary of this chapter and a preview of the fifth chapter.

\section{Restatement of the Purpose}

The purpose of this study was to investigate the influence of cooperative learning approach on below average learners. In order to examine the effects of cooperative learning on these students, three areas were studied: spelling achievement, self-concept, and locus of control. Additionally, three major null hypotheses were advanced to determine if the treatment, cooperative learning, significantly raised the performance of the students in the three areas over a six-week treatment period.

\section{Analyses of the Hypotheses}

\section{Null Hypothesis One}

The first null hypothesis was that there would be no significant difference in spelling achievement between a group of below average, third grade students who experienced cooperative learning and a similar group who did not experience such learning. Furthermore, sub-hypothesis 1.1 stated that there would be no significant difference between males who experienced cooperative learning and males who did not. Hypothesis 
1.2 was that there would be no significant difference between the females who experienced cooperative learning and those who did not. The pretest and posttest means for the students appear in Table 5 . This table reflects that the experimental group averaged 39.19 percent correct on the spelling pretest and 79.29 percent on the posttest. The control group averaged 43.83 percent on the pretest and 65.74 percent on the posttest.

Table 5

Pretest and Posttest Means on the Spelling Test for the Treatment Groups and the Genders

\begin{tabular}{|c|c|c|c|c|c|c|}
\hline & $\begin{array}{l}\text { Pretest } \\
\text { Male }\end{array}$ & ¿Female & iMean & $\begin{array}{l}\text { Posttes } \\
\text { Male }\end{array}$ & ¿Female & 'Mean \\
\hline Experimental & $\begin{array}{c}36.17 \% \\
(23)\end{array}$ & $\begin{array}{c}41.96 \% \\
(25)\end{array}$ & $\begin{array}{c}39.19 \% \\
(48)\end{array}$ & $\begin{array}{c}74.43 \% \\
(23)\end{array}$ & $\begin{array}{c}83.76 \% \\
(25)\end{array}$ & $\begin{array}{c}79.29 \% \\
(48)\end{array}$ \\
\hline Control & $\begin{array}{c}45.67 \% \\
(27) \\
\end{array}$ & $\begin{array}{c}42.00 \% \\
(27)\end{array}$ & $\begin{array}{c}43.83 \% \\
(54)\end{array}$ & $\begin{array}{c}67.33 \% \\
(27)\end{array}$ & $\begin{array}{c}64.15 \% \\
(27)\end{array}$ & $\begin{array}{c}65.74 \% \\
(54)\end{array}$ \\
\hline
\end{tabular}

Table 6 presents the mean gains for the groups from pretest to posttest. As seen in this table, the 23 males in the experimental group gained 38.26 percentage points from pretest to posttest while the 27 control males gained 21.66 percentage points. The 25 experimental females gained 41.80 percentage points as the 27 control females gained 22.15 percentage points. The overall mean gain for the experimental 
group was 40.10 percentage points while the overall mean gain for the control group was 21.91 percentage points.

Table 6

Gain Scores for the Spelling Test Comparing

Treatment Groups and Genders

\begin{tabular}{|c|c|c|c|}
\hline & Males & 'Females & Mean \\
\hline $\begin{array}{l}\text { Experimental } \\
\text { Group }\end{array}$ & $\begin{array}{c}38.26 \% \\
(23)\end{array}$ & $\begin{array}{c}41.80 \% \\
(25)\end{array}$ & $\begin{array}{c}40.10 \% \\
(48)\end{array}$ \\
\hline $\begin{array}{l}\text { Control } \\
\text { Group }\end{array}$ & $\begin{array}{c}21.66 \% \\
(27)\end{array}$ & $\begin{array}{c}22.15 \% \\
(27)\end{array}$ & $\begin{array}{c}21.91 \% \\
(54)\end{array}$ \\
\hline
\end{tabular}

Table 7 contains the analysis of covariance for the spelling test comparing grouping and gender. This table presents the amount of variance accounted for each independent variable (groups or genders). If a significant amount of variance has been accounted for by the independent variable, then the independent variable is said to have had a significant effect. To determine if a significant amount of variance has been accounted for or to determine if there has been a significant effect, a $F$ ratio is generated. If the $F$ ratio seaches a predetermined level, a significant effect is denoted.

As can be seen in Table 7, the covariate, which was the pretest score for each individual, accounted for a significant amount of 
variance $(F(1,97)=38.87, p<0.01)$. There was a significant effect due to grouping $(F(1,97)=17.00, p<0.01)$. This statistic occurs by chance alone less than one time in a 100. There were no significant differences between the genders $(F(1,97)=0.36, p>0.05)$.

A test of simple main effects was calculated to specifically evaluate null hypotheses 1.1 and 1.2. In Table 7, the test between the experimental males is listed at the @ Males line and for females at the @ Females line. This test indicates that there was a significant difference $(F(1,97)=4.62, p<0.05)$ between the experimental and control males. There was also a significant difference $(F(1,97)=13.52$, $p<0.01)$ between the experimental and control females.

Since there was a significant difference between the experimental and control groups, examination of the gain scores indicates that the experimental group (mean gain $=40.10$ percent) scored significantly higher than the control group (mean gain $=21.91$ percent). The experimental males (mean gain $=38.26$ percent) scored significantly higher than the control males (mean gain $=21.66$ percent). The experimental females (mean gain $=41.80$ percent) also scored significantly higher than the control females (mean gain $=22.15$ percent).

Since there is a significant difference between the experimental and control groups, in terms of spelling achievement, null hypothesis one is rejected. Furthermore, null hypothesis 1.1 , which evaluated whether experimental and control males significantly differed in spelling achievement, is rejected due to the significant differences between the two male groups. Null hypothesis 1.2 , which evaluated 
whether experimental and control females significantly differed in spelling achievement, is also rejected.

Table 7

Analysis of Covariance and Test of Simple Main Effects

for the Spelling Test Comparing the Performance

of the Treatment Groups and Genders

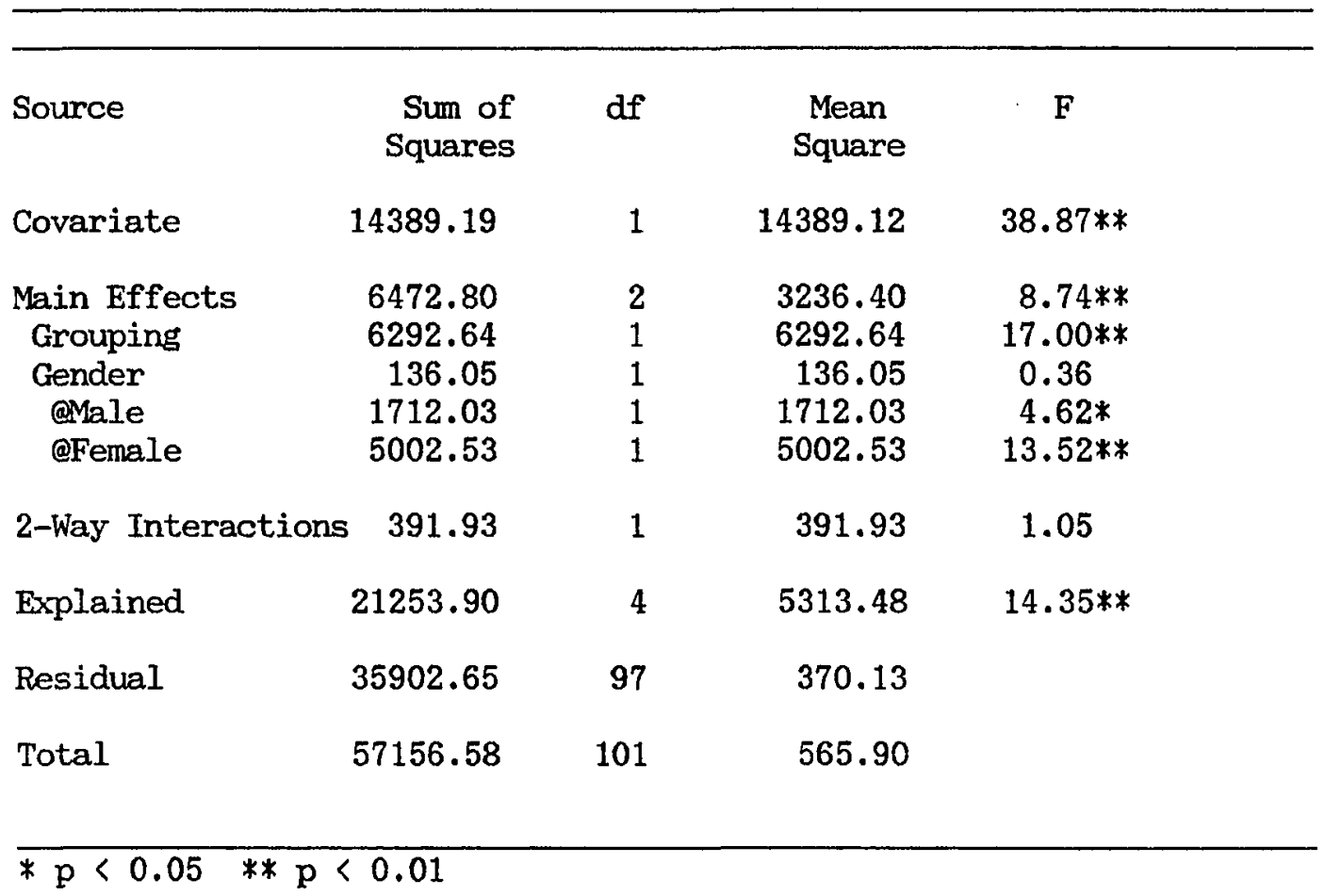




\section{Null Hypothesis Two}

The second null hypothesis stated that there would be no significant difference shown in self-concept between a group of below average students in the third grade who experienced cooperative learning and control students who did not experience such learning as measured by the Piers-Harris Self-Concept Scale. Subhypothesis 2.1 was that there would be no significant difference in self-concept between the males who experienced cooperative learning and those who did not. Subhypothesis 2.2 stated that there would be no significant difference in self-concept between the females who experienced cooperative learning and those who did not.

Table 8 contains the pretest and posttest means in self-concept scores for the groups and genders. As seen in this table, the experimental group averaged 57.54 points out of 80 points on the pretest and 62.10 on the posttest. The control group averaged 60.16 on the pretest and 62.05 on the post. The experimental males went from a pretest average of 57.50 to a posttest average of 63.64 . The control males scored 61.92 points at the pretest and 60.92 at the posttest. The gain scores, seen in Table 9, offer a picture of the changes in performances of the two groups.

Table 9 presents the gain scores for the treatment groups and genders. As seen in this table, while the experimental males gained 6.14 points from pretest to posttest, the control males lost one point between the two testing times. The gain for the experimental females (3.00) was lower than that achieved by the control females (4.78). 
Table 8

Pretest and Posttest Means for the Treatment Groups and Genders on the Piers-Harris Self-Concept Inventory

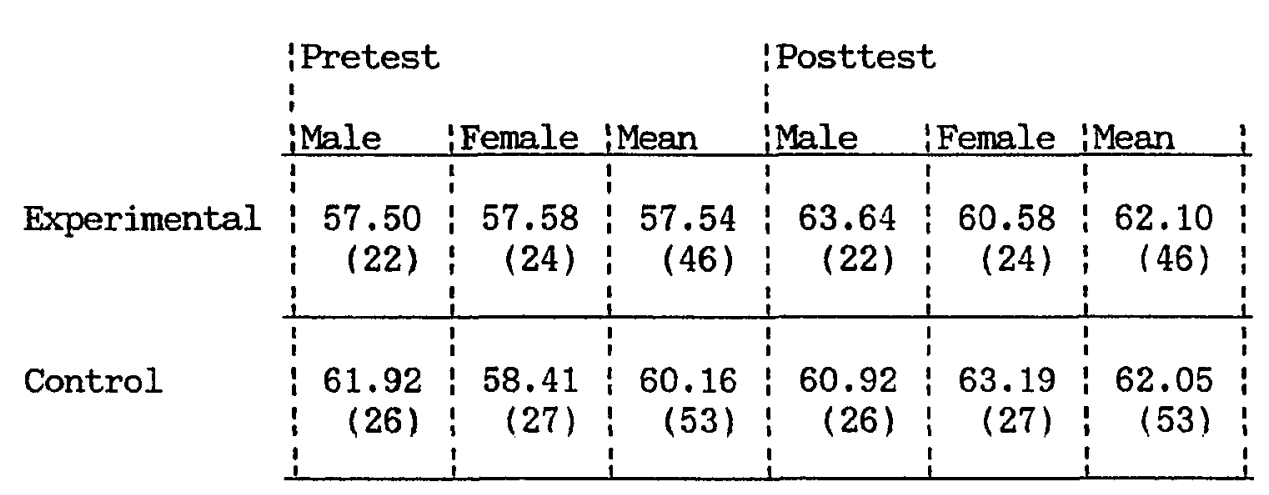

Table 9

Gain Scores for the Piers-Harris Self-Concept Inventory

Comparing Treatment Groups and Genders

\begin{tabular}{l|cc:c:c} 
& & & & \\
& & & & \\
& Males & Females & Mean \\
\cline { 2 - 5 } Experimental & 6.14 & 3.00 & 4.56 \\
Group & $(22)$ & $(24)$ & $(46)$ \\
& & & \\
Control & -1.00 & 4.78 & 1.89 \\
Group & $(26)$ & $(27)$ & $(53)$ \\
& & & &
\end{tabular}


Table 10 contains the analysis of covariance comparing the performances of the groups and genders in self-concept. As can be seen in this table, the covariate, which was the pretest score of the individual, accounted for a significant amount of variance $(F(1,94)=$ $61.38, p<0.01)$. The $F$ ratio for the grouping variable did not reach the pre-determined level of significance $(F(1,94)=0.92, p>0.05)$. The fact that the grouping variable was not significant indicates that the experimental and control groups did not significantly differ. There was also no significant difference between the genders $\langle F(1,94)=0.36, p\rangle$ $0.05)$.

However, the $\mathrm{F}$ ratio for the interaction did reach the predetermined level of significance $(F(1,94)=4.22, p<0.05)$. A significant interaction indicates that the effect of the treatment was not equally consistent for both males and females. This goes along with the fact that the experimental males showed a positive growth from pretest to posttest (mean gain $=6.14$ ) as did the experimental females (mean gain $=3.00)$. However, the control males (mean gain $=-1.00$ ) and the control females (mean gain $=4.78$ ) did not show consistently positive growth.

Since a significant interaction occurred, a test for simple main effects was calculated. This statistical analysis results in two important comparisons being made with this data. The first statistical comparison is between the experimental males and the control males. The second is the comparison of experimental females against the control females. These two comparisons allow statistical testing of the 
sub-hypotheses. From these two portions of the test of simple main effects, the two sub-hypotheses are rejected or accepted.

Table 10

Analysis of Covariance and Test of Simple Main Effects on the PiersHarris Self-Concept Inventory Comparing the Performance of the Groups and Genders

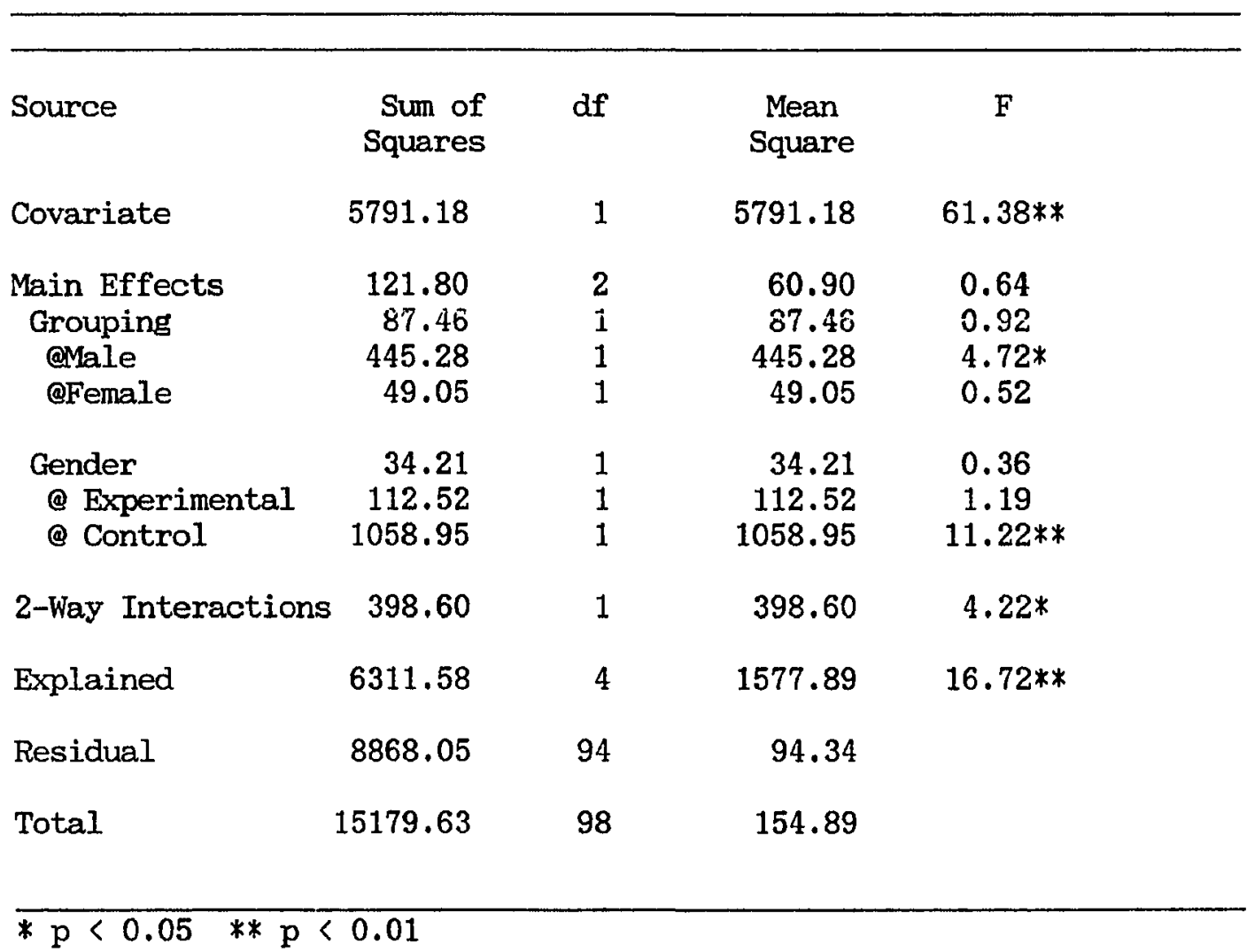

The test of simple main effects appears as part of Table 10. This analysis reflects that when only males are compared, there is a significant difference between the experimental and control group $(F(1,94)=4.72, p<0.05)$. Further, the experimental males score 
significantly higher (mean gain $=6.14$ ), as reflected by Table 9 , than the control males (mean gain $=-1.00$ ). When only females are compared, there is no significant difference $(F(1,94)=0.52, p>0.05)$. In this case, the experimental females (mean gain $=3.00$ ) scored lower than the control females (mean gain $=4.78$ ).

Since there was no significant difference between the experimental and control groups, null hypothesis two is accepted. However, through the analysis of the significant interaction, a significant difference was noted between the experimental and control male participants, and sub-hypotheses 2.1 is rejected. Since there is no significant difference between the experimental and control female participants, sub-hypothesis 2.2 is accepted.

Null Hypothesis Three

The third null hypothesis was that there would be no significant difference shown in the locus of control measure between a group of below average students in the third grade who experienced cooperative learning and a group who did not. Subhypotheses 3.1 stated that there would be no significant difference between the males who experienced cooperative learning and those males who did not in terms of their locus of control scores. Subhypotheses 3.2 stated that there would be no significant difference between the females who experienced cooperative learning and those who did not in terms of their locus of control scores.

Table 11 contains the pretest and posttest means for the groups by genders. As reflected by this table, the experimental group averaged 
20.05 on the pretest and 20.50 on the posttest. The control group averaged 17.61 on the pretest and 17.48 on the post.

Table 12 contains the gain scores for the treatment groups and the genders. As noted in this table, while the experimental males (mean gain $=-0.05$ points) and the control males (mean gain $=0.65$ ) did not reflect great differences, the experimental females (mean gain $=0.96$ ) appeared to have very different gains than the control females (mean gain $=-0.92$ points). Table 13 presents the analysis of covariance and test of simple main effects for the IAR results.

Table 11

Pretest and Posttest Means for the Treatment Groups and Genders on the Intellectual Achievement Responsibility Scale

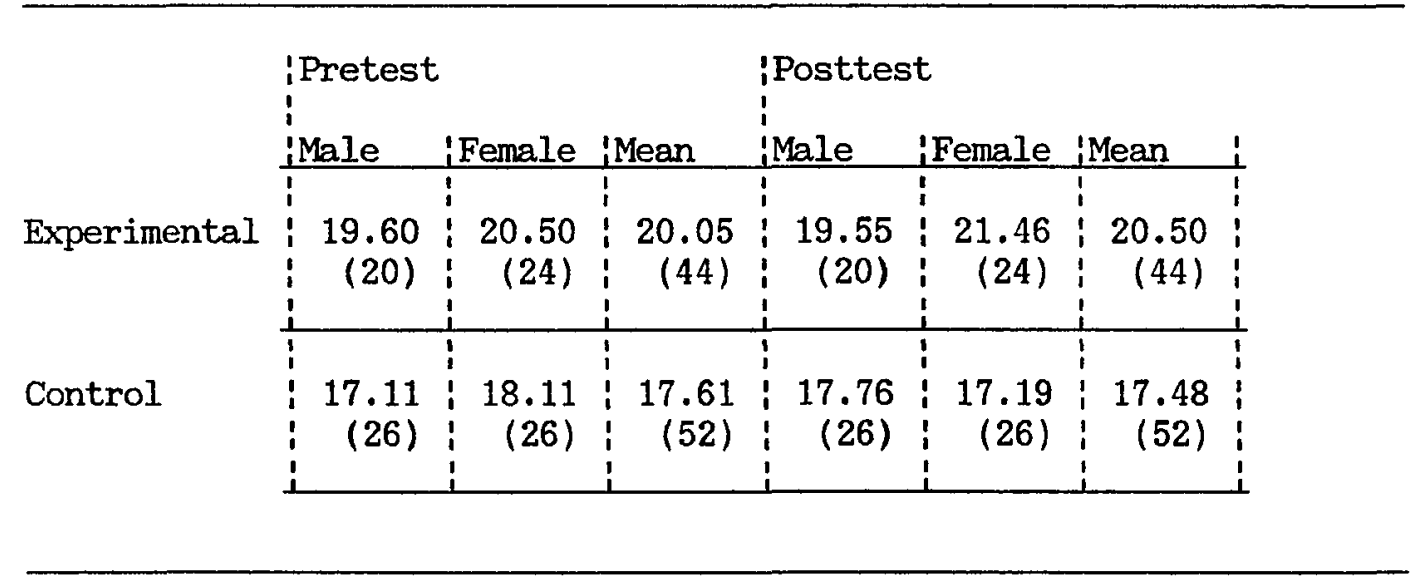


Table 12

Gain Scores for the Intellectual Achievement Responsibility

Scale Comparing Treatment Groups and Genders

\begin{tabular}{|c|c|c|c|}
\hline & imales & Females & Mean \\
\hline $\begin{array}{l}\text { Experimental } \\
\text { Group }\end{array}$ & $\begin{array}{r}-0.05 \\
(20)\end{array}$ & $\begin{array}{l}0.96 \\
(24)\end{array}$ & $\begin{array}{l}0.45 \\
(44)\end{array}$ \\
\hline $\begin{array}{l}\text { Control } \\
\text { Group }\end{array}$ & $\begin{array}{l}0.65 \\
(26)\end{array}$ & $\begin{array}{r}-0.92 \\
(26)\end{array}$ & $\begin{array}{r}-0.13 \\
(52)\end{array}$ \\
\hline
\end{tabular}

As is reflected in Table 13 , the F ratio $(61.89)$ indicates that the covariate accounted for a significant amount of variance $(F(1,91)=$ $61.89, p<0.01)$. There is a significant effect due to grouping $(F(1,91)$ $=6.70, p<0.01)$. Examination of the gain scores, in Table 12, shows that the experimental group (mean gain $=0.45$ ) scored significantly higher than the control group (mean gain $=-0.13$ ). Since there is a significant difference between the groups, the third null hypothesis is rejected.

Table 13 also portrays the fact that there is a no significant difference between males and females in their locus of control scores $(F(1,91)=0.01, p>0.05)$. In addition, there is a significant interaction of grouping and gender $(F(1,91)=4.05, p<0.05)$. Since a significant interaction occurred, a test for simple main effects 
was calculated. This statistical test computes comparisons between the experimental and control males, and the experimental and control females.

Table 13

Analysis of Covariance and Test of Simple Main Effects on the Intellectual Achievement Responsibility Scale Comparing the Performance of the Groups and Genders

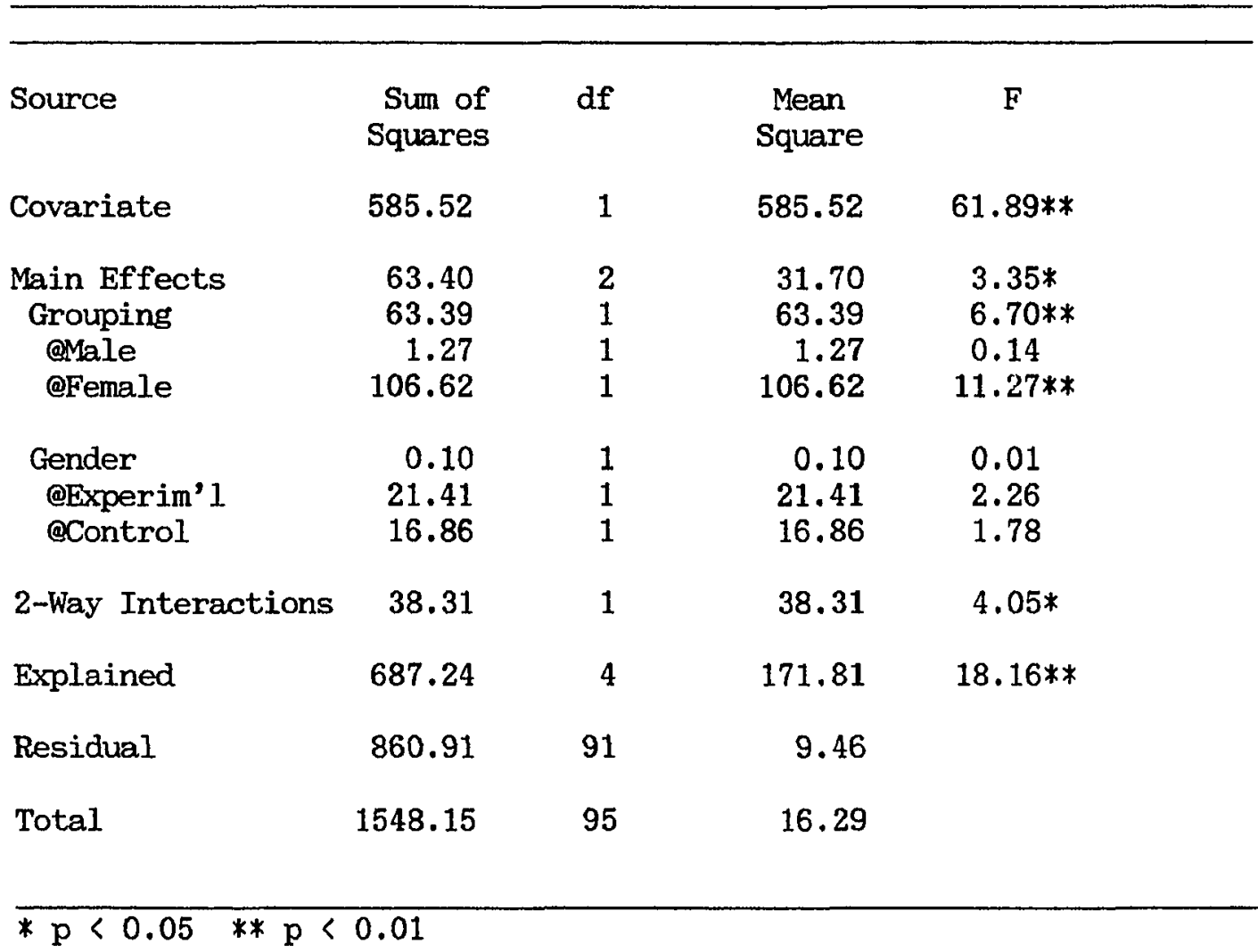


The results indicate that when only males are compared, the $\mathrm{F}$ ratio (0.14) does not reach the pre-determined value and reflects that there is no significant difference between the experimental and control group $(F(1,94)=0.14, p>0.05)$. When only females are compared, the $F$ ratio (11.27) does reach the pre-determined value. This $F$ ratio connotes that there is a significant difference $(F(1,94)=11.27, p<0.05)$ between the experimental and control groups. In this case, the experimental females (mean gain $=0.96$ ) scored significantly higher than the control females (mean gain $=-0.92$ ).

Since there was a significant difference between the experimental and control groups on their scores on the IAR, null hypothesis three is rejected. Furthermore, there was a significant interaction and a significant difference was noted. In terms of the difference between the experimental and control males, there is no significant difference. As a result sub-hypothesis 3.1 is accepted. For females, the experimental females significantly outscored the control females. As a result, sub-hypothesis 3.2 is rejected.

\section{Related Analyses}

To provide greater understanding of the relationships that exist between the variables in this study, further analyses were conducted to identify significant relationships. The researcher was also interested in determining if the school site at which an experimental or control students were housed altered the impact of cooperative learning on their responses. 


\section{Impact of Site}

One of the early concerns expressed in this study was to examine whether the school site from which the students and teachers came played any role in the performance of the students. As a result, an analysis of covariance was computed to examine the effect of site on the spelling performance of the students.

The means of the pretests, posttests and gains for spelling, considering the experimental and control groups and the two sites, are contained in Table 14. Although efforts had been taken to assure equality of the participating students by carefully selecting school sites and randomly assigning teachers to classes, there are noticeable differences in the pretest scores of the groups.

Table 14

Pretest and Posttest Means and Gain Scores for the Treatment Groups at the Sites on the Spelling Test

\begin{tabular}{|c|c|c|c|c|c|c|}
\hline & $\begin{array}{l}\text { iPretest } \\
\text { isite } \\
\text { ione }\end{array}$ & $\begin{array}{l}\text { iSite } \\
\text { iTwo }\end{array}$ & $\begin{array}{l}\text { 'Posttest } \\
\text { isite } \\
\text { ine } \\
\end{array}$ & $\begin{array}{l}\text { iSite } \\
\text { iTwo }\end{array}$ & $\begin{array}{l}\text { Gain } \\
\text { Site } \\
\text { SOne } \\
\end{array}$ & $\begin{array}{l}\text { Site } \\
\text { iTwo }\end{array}$ \\
\hline Experimental & $\begin{array}{c}33.06 \% \\
(35)\end{array}$ & $\begin{array}{c}55.69 \% \\
(13)\end{array}$ & $\begin{array}{c}75.97 \% \\
(35)\end{array}$ & \begin{tabular}{c|c}
$88.23 \%$ \\
$(13)$
\end{tabular} & $\begin{array}{c}42.91 \% \\
(35)\end{array}$ & $\begin{array}{c}32.54 \% \\
(13)\end{array}$ \\
\hline Control & $\begin{array}{c}52.36 \% \\
(14)\end{array}$ & $\begin{array}{c}40.85 \% \\
(40) \\
\end{array}$ & $\begin{array}{c}87.57 \% \\
(14) \\
\end{array}$ & $\begin{array}{c}58.10 \% \\
(40) \\
\end{array}$ & $\begin{array}{r}35.21 \\
(14)\end{array}$ & $\begin{array}{c}17.25 \% \\
(40\rangle\end{array}$ \\
\hline
\end{tabular}


The correct procedure to handle these differences (Isaacs and Michael, 1983) is the use of analysis of covariance. This point, cited earlier, is that the analysis of covariance equates the groups statistically so that the analysis determines the effects of the treatment despite major differences in pretest scores. The analysis of covariance for the sites and groups is displayed in Table 15.

The significant difference $(F(1,97)=6.68, p<0.01)$ between the experimental and control groups as discussed earlier continues to be present. At the same time, there is a significant difference between the two sites $(F(1,97)=9.06, p<0.01)$. Examination of the gain scores indicates that the students at the first site (which contained two of the three experimental groups) scored significantly higher (42.91 percent and 35.21 percent, experimental and control groups, respectively, and overall gain $=40.71$ percent $)$ in spelling than the students at the second site $(32.54$ percent and 17.25 percent, experimental and control groups, respectively, and overall gain $=21.75$ percent).

Furthermore, as displayed in Table 15, there is a significant interaction of group and site $(F(1,97)=10.14, p<0.01)$. Due to this, a test of simple main effects was computed and appears within this table. As this test reflects, there is no significant difference between the experimental and control groups at site one $(F(1,97)=0.29, p>$ $0.05)$, but there is a significant difference between the experimental and control groups at site two $(F(1,97)=17.33, p<0.01)$. Examination of the gain scores in Table 14 illustrates that the experimental group 
at site two (mean gain $=32.54$ percent) scored significantly higher than the control group at that site (mean gain $=17.25$ percent).

Furthermore, though the experimental groups at the two sites did not significantly differ $(F(1,97)=0.14, p>0.05)$, the two control groups did $(F(1,97)=19.62)$. The control group at the first site (mean gain $=35.21$ ) scored significantly higher than the control group at the second site (mean gain $=17.25)$. These results appear to indicate that site impacted the achievement of the students in spelling.

Table 15

Analysis of Covariance and Test of Simple Main Effects on the Spelling Test Comparing the Performance of the Groups at the Sites

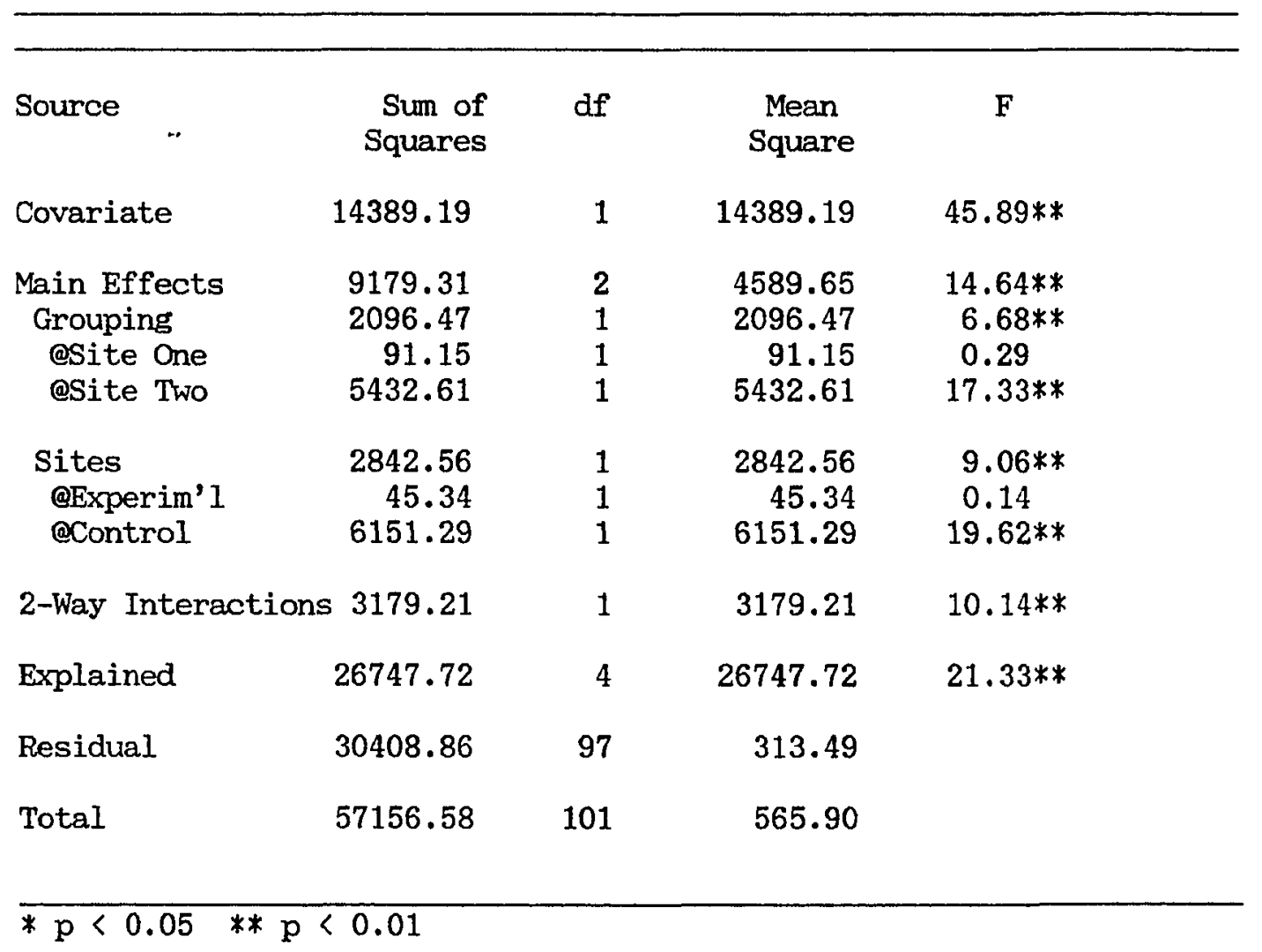


In previous discussion (p.79) and displayed in Table 13, it was shown that the experimental group significantly outperformed the control group on IARS scores due primarily to the superior performance of the experimental female students. In the current analysis, the scores of the experimental and control groups on the IARS are considered for the two school sites. The pretest and posttest means for the experimental and control groups and the two sites appear in Table 16, where the gain for the experimental students at site two (mean gain $=2.18$ points) seems very pronounced.

Table 16

Pretest and Posttest Means and Gain Scores for the Groups at the Sites on the Intellectual Achievement Responsibility Scale

\begin{tabular}{|c|c|c|c|c|c|c|}
\hline & $\begin{array}{l}\text { Pretest } \\
\text { Site } \\
\text { One }\end{array}$ & $\begin{array}{l}\text { iSite } \\
\text { iTwo } \\
\end{array}$ & $\begin{array}{l}\text { Posties } \\
\text { isite } \\
\text { One }\end{array}$ & $\begin{array}{l}\text { isite } \\
\text { iTwo } \\
\text { iTwo }\end{array}$ & $\begin{array}{l}\text { Gain } \\
\text { isite } \\
\text { One } \\
\end{array}$ & $\begin{array}{l}\text { ISite } \\
\text { 'Two }\end{array}$ \\
\hline Experimental & $\begin{array}{r}20.45 \\
(33)\end{array}$ & $\begin{array}{r}19.00 \\
(11)\end{array}$ & $\begin{array}{r}20.39 \\
(33)\end{array}$ & $\begin{array}{r}21.18 \\
(11)\end{array}$ & $\begin{array}{r}-0.06 \\
(33)\end{array}$ & $\begin{array}{l}2.18 \\
(11)\end{array}$ \\
\hline Control & $\begin{array}{r}20.08 \\
(12)\end{array}$ & $\begin{array}{r}16.88 \\
\quad(40)\end{array}$ & $\begin{array}{r}20.08 \\
(12)\end{array}$ & $\begin{array}{r}16.70 \\
(40)\end{array}$ & $\begin{array}{l}0.00 \\
(12)\end{array}$ & $\begin{array}{r}-0.18 \\
(40)\end{array}$ \\
\hline
\end{tabular}

The analysis of covariance, presented in Table 17, indicates that there is a significant main effect $(F(2,91)=3.38, p<0.05)$ caused either by a significant difference between the experimental and control groups or the two sites. The table indicates that the previously noted 
significant difference between the experimental and control groups continues to be present $(F(1,91)=5.14, p<0.05)$.

Table 17

Analysis of Covariance and Test of Simple Main Effects on the

Intellectual Achievement Responsibility Scale Comparing the

Performance of the Groups at the Two Sites

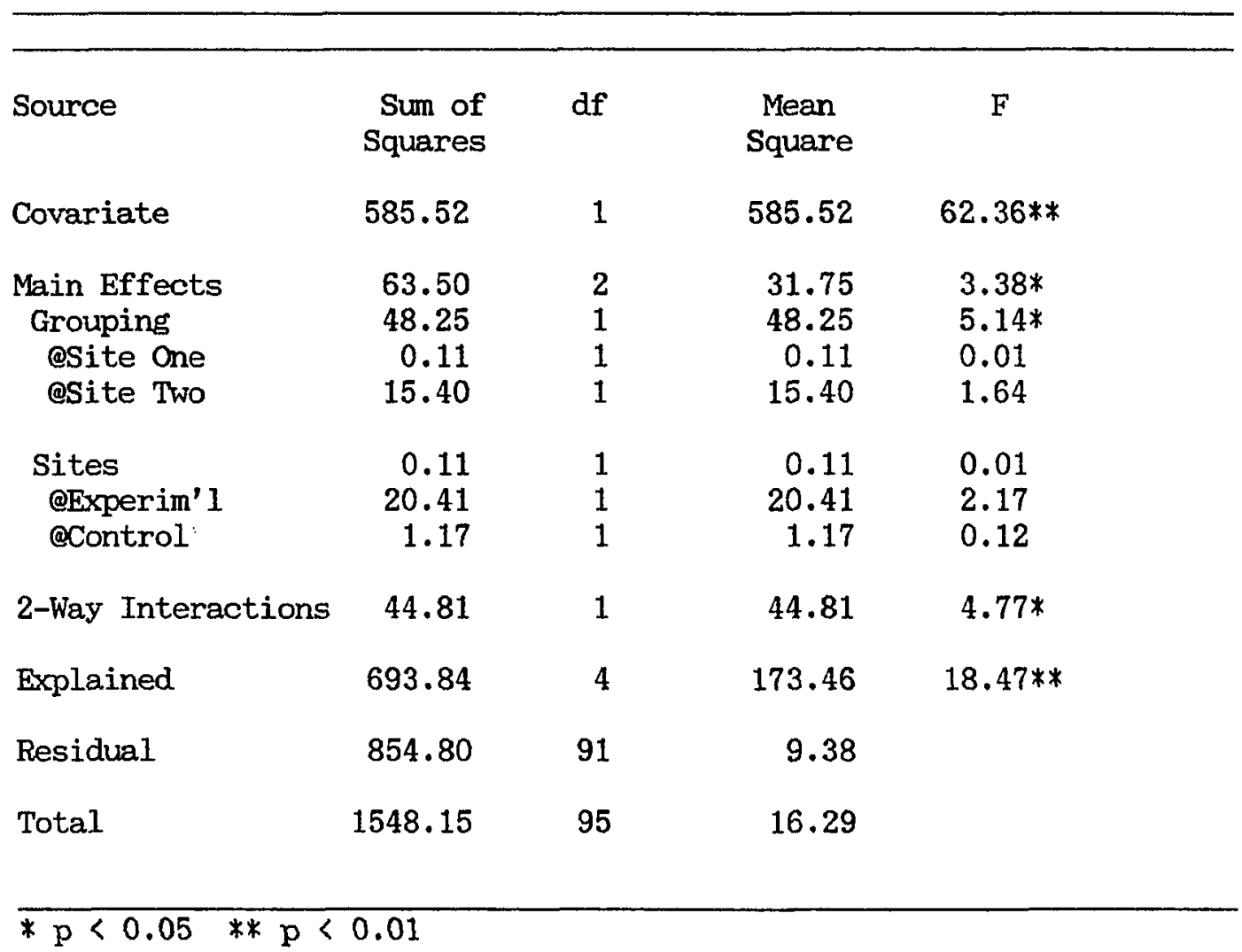

However, there is no significant difference between the two sites $(F(1,91)=0.01, p>0.05)$, but there is a significant interaction $(F(1,91)=4.77, p<0.05)$. This significant interaction usually means that one of the groups did or did not change equally to the others. The 
test of simple main effects, which is seen in Table 17, was calculated to determine where any significant differences occurred.

As seen in Table 17, there is no significant difference on the test of simple main effects between the experimental and control groups at site one $(F(1,91)=0.01, p>0.05)$ nor at site two $(F(1,91)=1.64, p>$ $0.05)$. There is also no significant difference between the experimental groups at sites one and two $(F(1,91)=2.17, p>0.05)$ nor between the control groups at sites one and two $(F(1,91)=0.12, \mathrm{p}>0.05)$. A significant interaction would normally indicate that students responded differently at the either site one or two, which would be identified by the test of simple main effects. However, the lack of significant differences on the test of simple main effects appears to be due to the relative closeness of the gains of the groups, resulting in the differences not reaching the 0.05 level of significance. The lack of significant differences appears to reflect that site did not play a definitive role for the experimental and control groups on this dependent measure.

Academic Level

While the majority of the demographic characteristics of the student sample are reported in Chapter Three, one factor was not addressed in this chapter. This factor is the distribution of the students in the first and second quartiles of academic performance. To display this information, students overall performance on the CTBS was classified as within Q1 (between the first and the twenty-fifth percentile), or within Q2 (above the twenty-fifth percentile and below the fiftieth percentile). A crosstabulation of student grouping 
(experimental or control) and student level (within Q1 or within Q2) was then tabulated. The results appear in Table 18. The Chi-Square statistic associated with this crosstabulation is not significant (Chi-Square = $0.92, p>0.05)$ reflecting that the experimental and control groups had equivalent numbers of Q1 and Q2 students.

Table 18

Crosstabulation of Student Grouping and Student Academic Level

Count

Row

Percentile

Experimental

Group

Control

Group

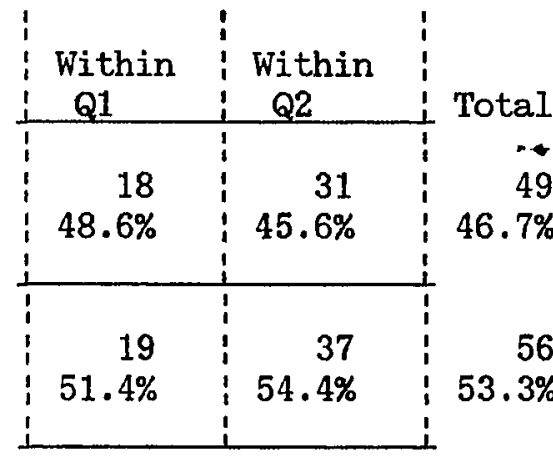

Total

$\begin{array}{rrr}37 & 68 & 105 \\ 35.2 \% & 64.8 \% & 100.0 \%\end{array}$

Chi-Square $=0.92, \mathrm{p}>0.05$

The scores from the three dependent measures were analyzed using ability level and group as independent variables. Table 19 portrays the pretest, posttest and gain scores. As seen in Table 20, a significant difference $(F(1,97)=17.77, p<0.01)$ was noted between the experimental and control groups on the spelling test, but not between the academic levels $(F(1,97)=0.02, p>0.05)$. While the differences 
between the groups were discussed earlier, the significant interaction $(F(1,97)=5.10, p<0.05)$ of the groups and levels indicates that the academic level of the student did have an impact on their spelling performance. As a result, a test of simple main effect was computed and is contained in Table 20.

Table 19

Pretest and Posttest Means and Gain Scores for the Treatment Groups at the Two Academic Levels on the Spelling Test

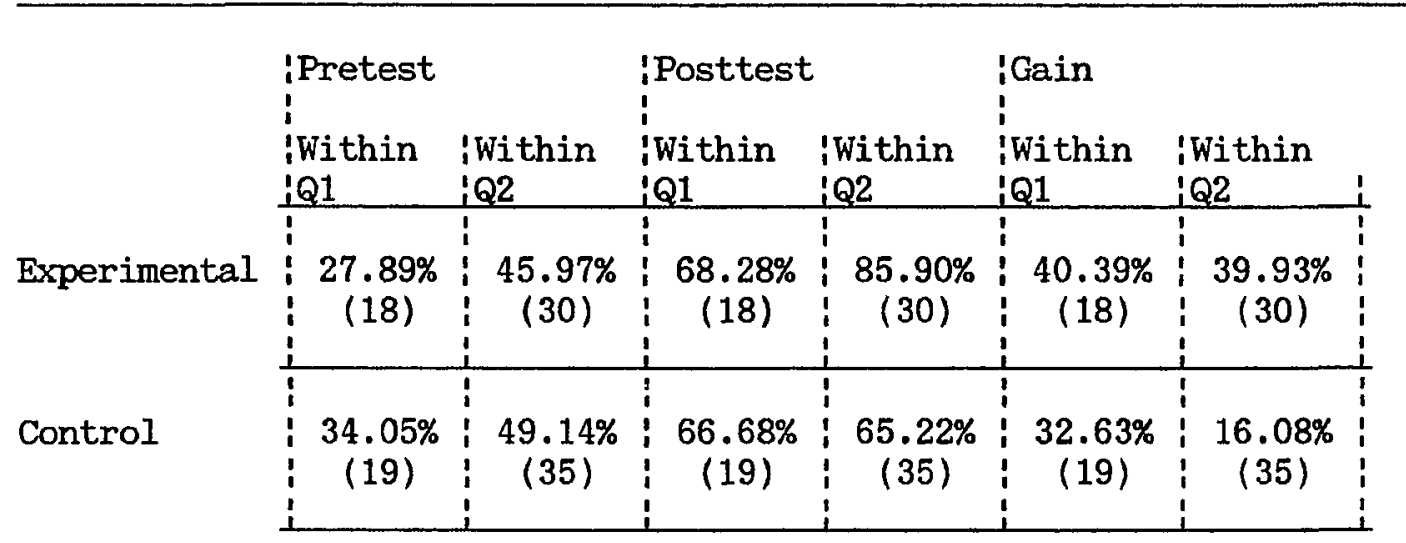

As reflected in Table 20, there is no significant difference $(F(1,97)=0.28, p>0.05)$ between the experimental and control students within Q1. But, there is a significant difference between the experimental and control groups within Q2 $(F(1,97)=11.03, \mathrm{p}<0.01)$. Examination of the gain scores in Table 19 indicates that the experimental students within Q2 (mean gain $=39.93$ percent) scored significantly higher than the control students within Q2 (mean gain = 16.08 percent). Furthermore, as seen in Table 20, there is no 
significant difference $(F(1,97)=2.37, p>0.05)$ between the experimental students within Q1 and Q2 nor between the control students within $\mathrm{Q} 1$ and $\mathrm{Q} 2(\mathrm{~F}(1,97)=2.74, \mathrm{p}>0.05)$.

As seen in Table 19, the experimental students (mean $=27.89$ percent) within Q1 scored lower on the pretest than the control students (mean $=23.04$ percent) in Q1. On the posttest, the Q1 experimental

Table 20

Analysis of Covariance and Test of Simple Main Effects on the Spelling Test Comparing the Performance of the Groups at the Two Academic Levels

\begin{tabular}{|c|c|c|c|c|}
\hline Source & $\begin{array}{r}\text { Sum of } \\
\text { Squares }\end{array}$ & df & $\begin{array}{c}\text { Mean } \\
\text { Square }\end{array}$ & $\mathrm{F}$ \\
\hline Covariate & 14389.19 & 1 & 14389.19 & $35.33 * *$ \\
\hline $\begin{array}{l}\text { Main Effects } \\
\text { Grouping } \\
\text { @Within Q1 } \\
\text { @Within Q2 }\end{array}$ & $\begin{array}{r}6344.60 \\
6338.82 \\
199.26 \\
7992.85\end{array}$ & $\begin{array}{l}2 \\
1 \\
1 \\
1\end{array}$ & $\begin{array}{r}3172.30 \\
6338.82 \\
199.26 \\
7992.85\end{array}$ & $\begin{array}{c}8.89 * * \\
17.76 * * \\
0.28 \\
11.03 * *\end{array}$ \\
\hline $\begin{array}{l}\text { Academic Level } \\
\text { @Experim'1 } \\
\text { @Control }\end{array}$ & $\begin{array}{r}7.85 \\
847.01 \\
980.74\end{array}$ & $\begin{array}{l}1 \\
1 \\
1\end{array}$ & $\begin{array}{r}7.85 \\
847.01 \\
980.74\end{array}$ & $\begin{array}{l}0.02 \\
2.37 \\
2.74\end{array}$ \\
\hline 2-Way Interactions & is 1819.38 & 1 & 1819.38 & $5.10 *$ \\
\hline Explained & 22553.18 & 4 & 5638.29 & $15.80 * *$ \\
\hline Residual & 34603.41 & 97 & 356.73 & \\
\hline Total & 57156.58 & 101 & 565.90 & \\
\hline
\end{tabular}


students (mean $=68.38$ percent) outperformed the $\mathrm{Q} 1$ control students. On the posttest, the control group had an average of 66.68 percent. This table also displays the fact that the experimental students (mean = 45.97 percent) within Q2 scored lower on the pretest than the control students (mean $=49.14$ percent) in Q2. On the posttest, the Q2 experimental students (mean $=85.90$ percent) outperformed the $\mathrm{Q} 2$ control students. On the posttest, the control group had not performed as well as the experimental Q2 students, ending with an average of 65.22 percent. The posttest performance of the control Q2 students was very similar to the performance of the control Q1 students.

Table 21 contains the pretest and posttest means for the groups and academic levels for the locus of control measure. As seen in this table, the experimental students in the first quartile (Q1) showed the greatest growth (mean gain $=0.88$ points. The analysis of covariance for this dependent variable appears in Table 22. As seen in this table, there is a significant difference between the groups $(F(1,91)=6.66, p<0.01)$ which has been discussed earlier. There is also a significant difference between the two academic level groups $(F(1,91)=4.17, p<0.05)$.

Examination of the gain scores indicates that the Q1 group (mean gain $=0.77$ ) scored significantly higher than the Q2 group (mean gain = -0.20 ) in terms of the locus of control measure. This demonstrates that the Q1 group scored significantly higher in locus of control than the Q2 group. Furthermore, there is no significant interaction of group and level $(F(1,91)=0.01, p>0.05)$. 
Table 21

Pretest and Posttest Means and Gain Scores for the Groups at the

Two Academic Levels on the Intellectual Achievement

\section{Responsibility Scale}

\begin{tabular}{|c|c|c|c|c|c|c|}
\hline & $\begin{array}{l}\text { Pretest } \\
\text { iQ1 }\end{array}$ & $\begin{array}{l}\text { iWithin } \\
\text { iQ2 }\end{array}$ & $\begin{array}{l}\text { Posttes } \\
\text { iQithin } \\
\text { iQ1 }\end{array}$ & $\begin{array}{l}\text { iWithin } \\
\text { iQ2 }\end{array}$ & $\begin{array}{l}\text { Gain } \\
\text { Within } \\
\text { :Q1 }\end{array}$ & $\begin{array}{l}\text { IWithin } \\
\text { QQ2 }\end{array}$ \\
\hline mental & $\begin{array}{r}20.94 \\
(17) \\
\end{array}$ & $\begin{array}{r}19.56 \\
(27)\end{array}$ & $\begin{array}{r}21.82 \\
(17)\end{array}$ & $\begin{array}{r}19.81 \\
(27)\end{array}$ & $\begin{array}{l}0.88 \\
(17)\end{array}$ & $\begin{array}{l}0.25 \\
(27)\end{array}$ \\
\hline ontrol & $\begin{array}{r}17.89 \\
(18)\end{array}$ & $\begin{array}{rr}1 & \\
1 & 17.47 \\
& (34)\end{array}$ & $\begin{array}{r}18.56 \\
(18)\end{array}$ & $\begin{array}{r}16.91 \\
(34)\end{array}$ & $\begin{array}{l}0.67 \\
(18)\end{array}$ & $\begin{array}{r}-0.56 \\
(34)\end{array}$ \\
\hline
\end{tabular}


Table 22

Analysis of Covariance for the Intellectual Achievement Responsibility

Scale Comparing the Performance of the Groups and

the Two Academic Levels

\begin{tabular}{lrrrr}
\hline & & & & \\
\hline Source & $\begin{array}{c}\text { Sum of } \\
\text { Squares }\end{array}$ & $\mathrm{df}$ & $\begin{array}{c}\text { Mean } \\
\text { Square }\end{array}$ & $\mathrm{F}$ \\
Covariate & 585.52 & 1 & 585.52 & $61.98 * *$ \\
Main Effects & 102.85 & 2 & 51.40 & $5.44 * *$ \\
Grouping & 63.00 & 1 & 63.00 & $6.66 * *$ \\
Academic Level & 39.45 & 1 & 39.45 & $4.17 *$ \\
2-Way Interactions & 0.14 & 1 & 0.14 & 0.01 \\
Explained & 688.51 & 4 & 172.12 & $18.22 * *$ \\
Residual & 859.63 & 91 & 9.44 & \\
Total & 1548.15 & 95 & 16.29 & \\
& & & & \\
\hline $\mathrm{p}<0.05$ & $* * \mathrm{p}<0.01$ & & & \\
\end{tabular}

\section{Summary}

This chapter has addressed the analyses of the hypotheses and has presented the related analyses. In terms of the original three null hypotheses advanced, the hypothesis addressing spelling achievement (null hypothesis one) was reje:cted. The sub-hypotheses evaluating performance spelling achievement for males (sub-hypothesis 1.1 ) and for females (sub-hypothesis 1.2) were also rejected. Null hypothesis two, which evaluated self-esteen changes, was accepted while the sub-hypothesis examining differences between the experimental and 
control males in the area of self-esteem was rejected (sub-hypothesis 2.1). The hypothesis examining the impact on locus of control (null hypothesis three) was rejected and as was sub-hypothesis 3.2 , which centered on differences between the experimental and control females in the area of locus of control.

In addition, several related analyses were computed to provide further information to clarify the role of site in the performance of the students as well as the impact of the students' academic level. Generally, neither site nor the students' academic level demonstrated a systematic impact on the results. In summary, this chapter has shown that the treatment did have a powerful impact on the performance of below average males and females primarily in the area of spelling achievement. Cooperative learning also had a noted impact on females in the area of locus of control. The next chapter examines the results in more detail. 


\section{CHAPTER FIVE}

Summary, Conclusions, Discussion and Recommendations

\section{Summary}

This study began with an introduction to research on learning styles. In examining this research, it was noted that few studies were focused on the elementary level (Pizzo, 1981; Krimski, 1982) with the majority aimed at the gifted student (Cross, 1982; Stewart, 1981) or on the secondary level (Cross, 1982, Wasson, 1981). Despite the lack of research specifically focused at the elementary level, researchers (Butler, 1984; Guild and Granger, 1985) continued to advocate the matching of teaching style with learning style.

Due to this continued emphasis on matching teaching approach with learning style, this study set out to determine the effects of matching teaching strategy and student learning style on the performance of Iow achieving students. The focus of the study was not on individualizing the learning experience but rather on examining the impact of a large group teaching strategy, cooperative learning (Johnson and Johnson, 1975; Kagan, 1985; Slavin, 1980), that closely matched the learning styles of the below average learners. To focus this effort, the purposes of the study were identified and null hypotheses advanced.

\section{The Purpose}

The three major purposes of this study were: 1) to determine how matching a ieashing stratezy with student learning style would affect the academic performance of below average students; 2 ) to examine the impact of this teaching strategy on the locus of control of the students; and, 3) to determine if the self-concept of the below average 
students would improve as a function of exposure to the teaching strategy. In following these purposes, three major null hypotheses and several sub hypotheses were advanced.

The first null hypothesis stated that there would be no significant difference in the spelling achievement of the experimental group of below average students who experienced cooperative learning and a control group of below average students who did not. The first subhypothesis in the area of spelling achievement examined whether experimental males differed from control males while the second subhypothesis evaluated whether experimental females differed from control females.

The second null hypothesis assessed whether the experimental group of students significantly differed from the control group in terms of scores on the Piers-Harris Self-Esteem Inventory. The first subhypothesis was focused on determining if the experimental males differed from the control males in terms of self-concept. The second subhypothesis questioned whether the experimental females differed from the control females in self-concept.

The third null hypothesis stated that there would be no significant difference between the experimental and control groups in locus of control as measured by their scores on the Intellectual Achievement Responsibility Scale. The first subhypothesis evaluated whether experimental and control males differed in locus of control. The third subhypothesis examined whether experimental and control females differed in locus of control. 


\section{Research Design}

This study occurred because the researcher, as an instructional leader, felt strongly that below average learners needed a different approach to their education due to their continued poor academic performances across their years in elementary school. As a result, the researcher began examining the literature on learning styles, looking for a possible solution. In addition, the researcher evaluated, in a pilot study, the learning styles of a number of below average learners and found that they appeared to have a consistent learning style.

In examining the literature (Guild and Granger, 1985), it becane apparent to the researcher that the learning style approach to educating children was flawed due to its requirement that learning be individualized. Since teachers needed teaching strategies that could be implemented, the researcher identified cooperative learning (Kagan, 1985 ) as a teaching approach that would closely match the learning styles of the students while allowing the teacher to work with large groups.

After identification of an appropriate instructional strategy, the researcher needed to determine if this alteration of teaching style would have an impact on below average learners. Six teachers at two public school sites in a large, urban school district in Southern California were contacted. By random assignment, two teachers at the first site were designated as the experimental teachers and one as a control teacher. One experimental and two control teachers were designated by random selection at the second site. The subjects were the boys and girls within the classrooms of the experimental teachers. 
The researcher, as an instructional leader, recognized the importance of appropriate inservice for implementing a new teaching approach as cooperative learning. The researcher identified the appropriate person from this large school district to provide the necessary training for the experimental teachers and coordinated the training for the teachers. The trainer specialized in cooperative learning and carried out the training for the teachers. Upon completion of the training, the teachers returned to their classrooms and began implementing cooperative learning approaches during their spelling programs, which the researcher had decided to focus on because of the use of the same texts and spelling words by all six teachers.

Prior to the onset of the use of cooperative learning in the classrooms, the students were pretested by their teachers. For the purposes of this study, the researcher had identified the appropriate assessment tools to use. Two standardized tests, the Piers-Harris Self-Esteem Inventory and the Intellectual Achievement Responsibility Scale, and a criterion referenced spelling test were administered to both the experimental and control students. After a six week classroom implementation period, the students were retested. The data were collected and collated by the researcher. They were then entered via data entry personnel onto a large, mainframe computer. On this mainframe, using SPSS-X (SPSS, Inc., 1986), the data were analyzed statistically to test the null hypotheses. Results

Table 23 summarizes the results of the analyses of the hypotheses. As seen in this table, the first null hypothesis was rejected, with the 
experimental students, who experienced cooperative learning, significantly outperforming in spelling achievement the control students, who did not experience cooperative learning. Sub-hypotheses 1.1 and 1.2 were also rejected indicating that the experimental males outperformed the control males, and that the experimental females outperformed the control females.

Null hypothesis two was accepted, indicating that, overall, the experimental and control groups had equivalent self-esteem scores at the end of the study. However, there was a significant interaction and the subsequent test of simple main effects indicated that the experimental males $\left(E_{M}\right)$ significantly outperformed the control males $\left(C_{M}\right)$, but that both the experimental and control females did not significantly differ. As a result of this analysis, sub-hypothesis 2.1 was rejected and sub-hypothesis 2.2 was accepted.

Table 23 (on p. 99) also displays the results for the analysis of null hypothesis three. As seen in this table, this hypothesis was rejected with the experimental group scoring significantly higher than the control group in the area of locus of control scores. Furthermore, there was a significant interaction which was analyzed with a test of simple main effects. From this test, it was determined that the experimental and control males did not significantly differ, but that experimental females $\left(E_{F}\right)$ scored significantly higher in locus of control than did the control females $\left(C_{F}\right)$. As a result, sub-hypothesis 3.1 was accepted and sub-hypothesis 3.2 was rejected. The significant difference between the females appeared to the reason why the third null hypothesis was rejected. 
Table 23

Summary of Results for the Null Hypotheses

\begin{tabular}{|c|c|c|c|}
\hline Hypothesis & $\begin{array}{l}\text { Independent } \\
\text { Variable }\end{array}$ & $\begin{array}{l}\text { Dependent } \\
\text { Variable }\end{array}$ & Outcome \\
\hline $\begin{array}{l}1 \\
1.1 \\
1.2\end{array}$ & $\begin{array}{l}\text { Group: E vs. C } \\
\text { Males: E vs. C } \\
\text { Females: E vs. C }\end{array}$ & $\begin{array}{l}\text { Spelling } \\
\text { Spelling } \\
\text { Spelling }\end{array}$ & $\begin{array}{l}\text { Reject: } E>C \\
\text { Reject: } E_{M}>C_{M} \\
\text { Reject: } E_{F}>C_{F}\end{array}$ \\
\hline $\begin{array}{l}2 \\
2.1 \\
2.2\end{array}$ & $\begin{array}{l}\text { Group: E vs. C. } \\
\text { Males: E vs. C } \\
\text { Females: E vs. C }\end{array}$ & $\begin{array}{l}\text { Self-Esteem } \\
\text { Self-Esteem } \\
\text { Self-Esteem }\end{array}$ & $\begin{array}{l}\text { Accept: } \\
\text { Reject: } E_{M}>C_{M} \\
\text { Accept: }\end{array}$ \\
\hline $\begin{array}{l}3 \\
3.1 \\
3.2\end{array}$ & $\begin{array}{l}\text { Group: E vs. C } \\
\text { Males: E vs. C } \\
\text { Females: E vs. C }\end{array}$ & $\begin{array}{l}\text { LOC } \\
\text { LOC } \\
\text { LOC }\end{array}$ & $\begin{array}{l}\text { Reject: } E>C \\
\text { Accept: } \\
\text { Reject: } E_{F}>C_{F}\end{array}$ \\
\hline
\end{tabular}

Note: $\quad$ LOC $=$ Locus of control

$\mathrm{E} \quad=$ Total experimental group

$\mathrm{C}=$ Total control group

$E_{M}=$ Experimental males

$\mathrm{C}_{\mathrm{M}}=$ Control males

$E_{F}=$ Experimental females

$C_{F}=$ Control females

In summary, of the three major null hypotheses advanced, the hypotheses addressing spelling and locus of control were rejected. In each of these cases, the experimental group significantly outperformed the control group. Furthermore, the experimental males significantly outperformed the control males in self-esteem while the experimental females significantly outscored the control females in locus of control. 


\section{Conclusions}

Based on the outcomes of this study, several conclusions can be drawn. The first conclusion is that cooperative leaming appears to have a powerful effect on below average learners. This conclusion is supported by the fact that two of the three null hypotheses (the first and the third, focusing on spelling and locus of control, respectively) were rejected, with the experimental group significantly outperforming the control groups on these measures.

The second conclusion is that males and females appeared to benefit equally from cooperative learning. More clearly stated, significant differences between boys or girls in the cooperative groups generally balanced out. This point is substantiated by the fact that: 1) experimental males and females significantly outscored control males and females in spelling achievement; 2) the experimental boys significantly outscored the control boys in self-concept while the experimental and control females did not significantly differ; and, 3) that the experimental girls significantly outscored the control girls in locus of control, while there were no significant differences between the boys. Restated, the results indicate that neither boys nor girls were systematically favored by the cooperative learning experience.

The third conclusion is that the treatment (cooperative learning) had its greatest impact on spelling achievement. This statement is supported by the fact that spelling was the one area in which both males and females in the experimental group outperformed the control students from pretest to posttest. In the area of locus of control, the 
significant difference between the experimental and control groups was due to the superior performance of the experimental females. In self-esteem, there was no significant difference between the groups but experimental males significantly outscored the control males.

The fourth conclusion, based on the experiences of the researcher, is that cooperative learning was very effective. While the statistical results support this contention, the personal responses of the teachers using cooperative learning was very positive. All three of the teachers implementing cooperative learning stated that they could note a very resounding change in their classrooms, in terms of how much their students mastered as well as in how the students got along.

They claimed that their classes seemed to run more smoothly during the times that cooperative apprcaches were used and this "smoothness" would carry over to lessons following the cooperative activities, despite the fact that the teachers were not using the techniques in the other periods. The researcher was also able to note this difference while viewing the classes. The three teachers vowed to use cooperative techniques next year in their spelling periods and to expand the number of periods in which cooperative methods would be used.

\section{Discussion}

This study examined the impact of matching the learning style of below average learners with a teaching strategy, cooperative learning, that closely paralleled the learning styles preferred by the below average students. In completing this study, the results, in terms of these students, seem to conform with existing research. More 
specifically, as Slavin (1980a) pointed out, the use of cooperative techniques assisted the attainment of higher academic performance of all the students in the experimental classes, but those outcomes have been primarily focused on reading skills.

\section{Spelling}

The current results, which showed significant gains in the area of spelling, are some of the first to show changes in the language arts areas. For example, Talmage, Pascarella, and Ford (1984) found that cooperative approaches resulted in higher performance in reading but not in language arts. Since spelling is usually subsumed under the general rubric of language arts (capitalization, punctuation, spelling and proper grammar usage), this present study did find very different results than did Talmage, Pascarella, and Ford (1984), even though both programs did teach factual information. The difference between the two studies could be due to three different factors.

First, in the Talmage, Pascarella, and Ford (1984) study, the authors did not use any specific, cooperative techniques, such as, STAD or TGT. In place of such structured techniques, they focused on ways of encouraging children to work together. This current study did use STAD and efforts were made to insure that all the experimental teachers did provide nearly equal amounts of training with the children. This difference, i.e., the high structure in this study and not in the Talmage, Pascarella, and Ford (1984) study, could have been the causative agent for the positive outcomes reported here and not in the other study. 
Second, Talmage, Pascarella, and Ford (1984) attempted to influence a very large academic area, language arts. Language arts, depending on the focus of the curriculum and the test, could include such diverse issues as spelling, punctuation, and dictionary and/or research slills. This present study was confined only to spelling and only to spelling as evaluated by the more traditional spelling test, e.g., "I say the word, say it in a sentence, and you (the student) write it". Thus, the discrepancies between the two studies could be merely a function of differing scopes.

Third, the Talmage, Pascarella, and Ford (1984) study really examined the performance of the students over a three year period. This present study was confined to a much shorter time. Due to the differences in the lengths of the studies, it is difficult to compare the two studies as directly as one would like. For one thing, this present study did not lose any students from pretest to posttest while Talmage, Pascarella, and Ford (1984) only had 58\% of the students remaining over this three year period. These remaining students might represent the more stable and intact families, which could have some impact on the students' academic achievement.

This present study is much closer to the results reported by Yager (1986). In his study, Yager worked with average third grade students over a three month period. Furthermore, Yager (1986) displayed changes in reading and spelling of the same magnitude as this present effort. The results of this study, then, are well in line with those cited by Yager (1986) as well as those reported in Johnson, et. al. (1981) and Slavin (1985). But the discrepancies between the current study and 
Talmage, Pascarella and Ford (1984) do point out the great need for more long term evaluations of cooperative learning to clearly determine if the impact of cooperative learning continues over longer periods of time.

In consideration of the typical classroom setting, this present study compares favorably with Johnson, et. al. (1981), Slavin \& Oickle (1981), Slavin (1985) and Yager (1986). These studies generally focused on the performance of students in the average classroom and indicated that cooperative learning had a positive impact on the academic performance of average students. However, this present study is the first to focus specifically on the performance of below average students and the first to indicate that cooperative learning may be a very appropriate way for assisting students who are below average learners.

The prior work of Kagan, et. al. (1985) provides further insight into the present study. In this earlier work, Kagan and his co-authors displayed learning gains by various ethnic groups for various content areas, e.g., for mathematics, for reading and for language arts. In some content areas, cooperative learning was very effective and the Hispanic students did experience growth beyond their non-Hispanic counterparts in their academic achievement. However, in other areas, the impact of cooperative learning was neutral. Apparently, in this current study, cooperative learning helped the students, no matter their ethnic background, to achieve significantly higher than they would have in the regular classroom.

The lack of agreement between this current study and the previous research (Johnson, et. al., 1981; Johnson, Johnson, \& Maruyama, 1983; 
Kagan, 1983; Slavin, 1985; and Hernandez and Descamps, 1986), which pointed out that cooperative learning was more effective for minority youth, may also be explained by one other factor. In this present study, all the participants scored below the fiftieth percentile in their academic performance. Some of these previous studies (Kagan, 1983; Slavin, 1985; and, Hernandez and Descamps, 1986) only examined the performance of minority students compared with majority students.

In such studies, the researchers reported the academic scores of the minority students but did not see the students as a group of below average learners, as they were viewed in this study. The failure of this study to conform to other research, in terms of improved outcomes for minority students, may be due to the fact these previous studies were confounding minority status with academic status. More specifically, these other studies may have, in fact, shown significant change for the below average learners, but these groups of below average learners may have been identified as minority individuals rather than as individuals who were performing below a specific academic level.

In these prior studies, as the students improved their achievement due to the cooperative learning experience, the researchers centered their studies on the minority status of the students rather than on their academic status. This means that these researchers (Kagan, 1983; Slavin, 1985; and, Hernandez and Descamps, 1986), might have considered having stated that cooperative learning was very beneficial for below average learners rather than focusing primarily on the minority background of the student participants. Using the idea that these other studies should have identified that the minority students were, in fact, 
below average learners, this current study fits well with this prior research due to the fact that the present participants, no matter their ethnic heritage, are probably very similar in academic skills to those minority students.

There is one point not yet made about the positive academic change in the experimental students. Research by various authors (Carbo, 1980; Shea, 1983; and, Virostlio, 1983) has shown that the closer the match between the learning style of the students and the teaching style the better the students perform academically. As in this previous research, this current study did show improved academic scores for students who had their learning styles more effectively matched. Since this was one of the central points on which the study was focused, the change in spelling, which was both statistically and practically significant, strongly supports the original contention of this study that matching learning styles by a large group teaching strategy would have positive impact on the students.

\section{Self-Esteem}

The overall outcomes of this study showed no significant overall gains in self-esteem for the experimental group, even though the experimental males did score significantly higher than the control males. Generally, the research on cooperative learning and self-esteem (Johnson, Johnson, \& Maruyama, 1983; Slavin, Leavy, \& Madden, 1984; Slavin, 1985) reported improvement in self-esteem after exposure to cooperative learning. Since the experimental males did show significant change, the question is why the females in the experimental group did not show equivalent growth in self-esteem. 
One possible source for this difference in this current study could be the length of the study. Although there was ample time to bring about change in the academic area, perhaps there was not adequate time for an alteration of self-esteem. Since the teachers focused primarily on spelling, growth in the area of self-esteem would be expected to be due to the students' perception of their improvement in spelling achievement or their increased interaction with other students. The alteration of the students' perception or increased interaction would be anticipated to require varying amounts of time to influence self-esteem.

It might be expected, then, that some of the students would be influenced by the experimental condition but not all. Apparently, this happened. Males in the cooperative learning group did show significantly higher growth in self-esteem than the control males, indicating that there was adequate time for this experimental group to change their attitude about their self-esteem. The length of the experiment might have been ample for the males to change their self-esteem scores because of the interaction of their (male) self-esteem and their recently improved academic performances.

This position receives very positive support from the work of Scheirer and Kraut (1979). In completing an extensive review of the literature connecting change in achievement and self-concept, these authors noted that underachieving students, particularly elementary boys, have more negative self-concepts than do higher achieving students. These authors also note that positive academic change has been strongly associated with positive change in self-esteem. Furthermore, in this current study, the experimental males had the lowest pretest 
percentage in spelling (pretest mean $=36.17 \%$ ) and on this self-esteem measure $($ pretest mean $=57.50)$, indicating that they were the lowest scoring group, overall, at the time of the pretest.

While the growth in spelling achievement was nearly equal for experimental males and females, the impact of such positive academic growth may have increased the experimental males' view of themselves and, in turn, increased their self-concept scores. In fact, in examining the differences in self-esteem scores, the experimental males (self-esteem mean gain $=6.14$ ) points did respond very favorably to the treatment, when compared to the control males (self-esteem mean gain $=$ $-1.00)$.

Based on what Scheirer and Kraut (1979) pointed out, one would anticipate that the male control students would maintain their low self-esteem due to the fact that they did not experience the more positive academic growth. This is what happened. The control males scored similarly from pretest to posttest while the experimental males scored higher, resulting in a significant difference between them. This result further supports the fact in the research (Scheirer and Kraut, 1979; and Potterbaum, Keith and Ehly, 1986) that change in academic performance is usually accompanied by change in self-concept.

However, in the literature on self-esteem (Potterbaum, Keith, \& Ehly, 1986), there is an on-going debate about the role of self-esteem in academic performance. According to Potterbaum, Keith, \& Ehly (1986), there appears to be no simple, causal relation between academic achievement and self-concept. Instead, there appear to be moderating variables that connect self-esteem and academic skills. In this present 
study, one factor that might be considered to be such a moderator is the sex of the child. Since the boys in the experimental group showed significant growth in their self-esteem over the course of study, gender appeared to play the role of a moderating variable for this age group.

This present study adds to this literature on self-esteem by tentatively identifying gender as one of the intervening variables that may, eventually, be identified as important in understanding the interconnection between self-esteem, academic performance, and teaching strategies. Furthermore, as stated earlier, research in most areas, such as self-esteem, needs to be evaluated over short periods of time, as in the present study, and over longer periods of time to be able to identify how powerful was the effect.

\section{Locus of Control}

The significant change in locus of control for the experimental group supports the idea that cooperative learning did more closely match the learning style of the below average female students. As Covington and Omelich (1984) stated, locus of control is one learning style that has been shown to have a consistent, positive relationship with academic achievement. This apparently occurred in this study. Since the cooperative teaching style more closely matched the learning style of these below average students, the students performed better academically. With this positive academic change, there was a positive change in their locus of control. This positive change was seen by their higher scores on the Intellectual Achievement Responsibility Scale indicating that the experimental females took more responsibility for their academic performance. 
At the same time, the summary of the literature completed by Cornett (1983) indicated that teaching, which was matched with the students' learning styles, resulted in positive affective changes. The results seen in locus of control in this present study parallels this general tone of the literature. An interesting note, in the current results, is that experimental females responded significantly better in their locus of control scores than did the control females in this area (as compared to the males). This may be a very important corollary of the use of cooperative learning.

More specifically, Webb (1984) reported that females in cooperative groups tended to be ignored and avoided by male counterparts. Concurrently, females in these groups also tended to accede to males and to be more responsive overall than males. While the current research did not examine male or female roles and behaviors in the group, the significant, more internalized scores of the experimental females appears to indicate that the females in the experimental group were beginning to feel more in control of their role and position within these classrooms.

Finally, though no correlations were computed to determine the quality of the statistical relationship between the academic gains and locus of control gains for the experimental group, the significant difference favoring the experimental group for both spelling and the experimental females on the locus of control measure seemed to parallel the research on locus of control (Covington and Omelich, 1984). This literature stated that there was a significant, positive relationship between locus of control and academic achievement. The results of this 
present study extend the research by showing similar changes in locus of control and academics within the experimental group.

\section{The Role of the Instructional Leader}

The outcomes of this study clearly point out the powerful role that an instructional leader can play on improving the performance of students. Far too often, teachers feel that a group of students just cannot achieve in their classroom. Instead, these students may become the topic of discussion in the teachers' lounge. Upon hearing such comments or upon disaggregation of scores on the standardized achievement tests, the instructional leader is faced with the task of working to bring change to the school site.

This present study reflects the positive impact an instructional leader can have. After hearing the concerns of teachers, the researcher examined a wide range of literature and decided that cooperative learning would be an instructional strategy that would best match the learning styles of the below average learners. After identifying this technique as offering a very positive potential for addressing the needs of the below average learners, the instructional leader took steps to implement this approach.

Bringing change was not without its costs. Time and effort needed to be expended to provide the best possible training for teachers. Teachers with interest in cooperative learning had to be identified, permission had to be granted by other administrators, and time for training had to be arranged. The costs, in terms of time and effort, exemplify the active role that the instructional leader needs to utilize in order to bring change to each academic site. 
The outcomes of this study clearly indicate that extensive efforts on the part of the instructional leader are well worth it. Not only did the below average students perform at a much higher level on the spelling as did the experimental females on the locus of control measures, but, the teachers implementing cooperative learning became enthusiastic about the technique and its impact on these students, who previously did not perform well in their classrooms. One teacher stated, "I can't believe the change in the students during spelling." At the close of the experimental period, the three teachers using cooperative learning were looking forward to the expansion of the use of cooperative techniques in their classrooms.

It appears that instructional leaders need to be taught how to implement cooperative learning so as to support its greater use within classrooms. A group of instructional leaders should use various training opportunities, e.g., inservice prior to the beginning of the school year, inservice after school, and inservice during the school year, to train teachers how to use cooperative learning. These various approaches should then be evaluated to determine which is most effective in getting teachers to use this technique. This is necessary because, often, it is only when the instructional leader provides strong leadership toward new techniques, that we see implementation on a day-to-day basis.

Minimally, instructional leaders need to be taught how to evaluate and coach teachers who are implementing cooperative learning. Cooperative classrooms are louder than traditional classrooms and there is more student movement and activity. These differences could result in an uninformed instructional leader chiding a teacher who is, in fact, 
implementing the most appropriate approach for the students that are being taught. Because of the significant results in spelling, it seems apparent that cooperative learning needs to be implemented more widely and instructional leaders need to be in a position to support this implementation.

Finally, the results of this study strongly suggest that a concentrated effort by the instructional leader can have excellent pay backs for the leader. Bringing positive changes, in academics and in teacher enthusiasm, are two outstanding demonstrations of the impact of the leader. More instructional leaders need to review the current status of their students and teachers, and take an active, positive role by training and supporting the implementation of new, appropriate classroom strategies.

\section{other Findings}

This study also reviewed the impact of site and academic level of the student on the performance of the experimental and control students. The results and discussion of site and academic level appear below. School Site

A conclusion, based on the data analysis, is that school site played a minor role. Though the students at the first site significantly outscored the second site in spelling achievement, this difference appears to be due to the poor performance of the control group at the second site. The control group at that site gained only 18 percentage points from pretest to posttest, as presented in Table 13, compared to the experimental group at the second site, who gained over 32 points. 
Likewise, the experimental group at the first site gained over 42 percentage points from their pretest compared to a 35 point gain for the control group at the first site. In general, since there were conflicting results between the two sites on various measures, it is concluded that the major impact appeared to be due to the experimental treatment rather than the influence of the site.

The limited impact of site was supported by the results in the area of locus of control. The significant interaction on the locus of control measure between group and site could not be statistically separated to clearly point out the impact of the school site. These facts further reinforce the idea that group, not site, had a consistent impact on the results.

\section{Academic Level}

The influence of the academic level of the student (Q1 or Q2) did not appear to be very systematic. This was demonstrated by several facts. First, the experimental Q2 students did outperform the control Q2 students in spelling, but no difference was noted between the Q1 students. Second, the experimental Q1 and Q2 students outscored the control Q1 and Q2 students in locus of control. Third, no difference was noted in the area of self-esteen for Q1 and Q2 students. Overall, the analyses did not indicate that being a Q1 or Q2 student would allow one to predict how a student would perform.

\section{Conclusion}

The use of cooperative learning appeared to have a very beneficial overall impact on the experimental students. Significant gains were made in spelling for all experimental students and in locus of control for 
experimental females while gender of the student did play a role, but not a very consistent one, favoring males in the area of self-esteem and females in locus of control. However, this research cannot specifically identify whether the changes that took place were due solely to matching the students' learning styles with a teaching style that more closely paralleled the students' learning styles, or if the results were due solely to the use of cooperative learning. Therefore, it would seem essential that future research attempt to identify which of these two is the more potent.

There is little doubt that cooperative learning did, in fact, more closely match the students' learning styles. Furthermore, the change in spelling scores and in locus of control scores does appear to support the contention that matching styles is a very important issue to consider when teaching below average students. Concurrently, cooperative learning has been shown to improve the academic performances of minority students. The current results expand the literature by reporting positive academic and locus of control outcomes for below average students.

The results do show that when students' learning styles are more closely matched by the teaching style, students do significantly better in typical classroom spelling assignments. The results also show that the learning styles approach can be implemented in a manner that does not demand an individualized approach. Instead, teachers might be well advised to find teaching approaches that more closely match the general learning styles of their children and implement them to help improve the academic performance of their students. 
Finally, the powerful role of the instructional leader can play was dramatically indicated by this study. The positive outcomes of this study support the concentrated efforts of the instructional leader to bring change to their instructional staff. Only through the direction and support of the instructional staff will necessary changes be implemented.

\section{Recommendations}

Several recommendations for future study are made below:

1. Future research should examine the long term results of implementations such as seen in this study in order to determine their impact by evaluating the academic achievement of participating students at later dates. This study showed very conclusively that short term gains were very possible. However, the next issue is to determine if the influence of such an approach has any long term effect on the students.

2. Research might examine the continued use of cooperative learning after such programs as this present one. If teachers continue to use the technique and generalize its use to other subjects, then the improvement of the performance of the students is so strong as to be very obvious to the teachers.

3. Future studies might also examine the impact of cooperative techniques on other areas beside spelling. Implementation in areas such as mastery of addition, subtraction, multiplication and division facts, which are so crucial to mathematical success, certainly needs to be evaluated. 
4. Research might also examine the impact of cooperative learning on the mastery of higher level thinking skills. To date, studies on cooperative learning have primarily examined mastery of the low level skills. A study of the impact of cooperative learning experiences on the thinking skills of students appears warranted.

5. Future efforts might consider the performance of the students above the fiftieth and below the eighty-fifth percentiles. Since a teacher needs to insure that all students achieve in the classroom, evaluation of this group seems crucial. This group, those between the fiftieth and eighty-fifth percentiles, are frequently overlooked, being neither special education students, nor gifted. Programs that benefit these students need to be identified and supported.

6. There are strong parallels in the academic experiences of culturally different youth and below average students. Both groups of students are frequently experience frustration because of poor academic achievement and both groups experience excessive drop out rates. Since the present study demonstrated significant improvement in spelling achievement for below average learners, an area of traditional weakness for linguistically and culturally different youth, this type of study needs to be replicated with culturally different students to determine the impact of cooperative learning on their spelling achievement.

7. Since there were significant gender differences on some of the measures, future research might examine the benefit/detriment of using cooperative approaches with different gender students. 
Perhaps, the proper use of cooperative techniques might achieve the major goal of the American society, equality for all.

8. This current study limited itself to a relatively short period of implementation. Studies need to examine length of implementation to determine if differing lengths of implementation have any impact on academic achievement. Such studies could clarify if there is an implementation length which would maximize learning.

9. A replication of this study to determine for which group of students cooperative learning is most beneficial needs to be completed. Are the students who respond well to cooperative learning primarily culturally different, primarily low achieving, or a combination of these two characteristics? Concurrently, a clarification of the interaction of the academic level of the students (Q1 or Q2) and cooperative learning would help to better insure that teachers and administrators would recognize what techniques to use with which groups of students.

\section{Final Statement}

This study began with the identification by the researcher that certain students, termed below average learners, were not profiting equally in school. The researcher identified that these below average students had specific learning styles which appeared to not be matched well by the teaching style of the traditional teacher. Through a review of the literature, cooperative learning was identified by the researcher as a teaching strategy that could be implemented on a large group basis and would match well the learning styles of the below average student. 
The researcher then decided to implement a training program for teachers and determine if cooperative learning had a beneficial impact on below average learners.

Analyses of the results of the implementation indicated significant, positive change in spelling achievement and locus of control scores for below average learners in classrooms implementing cooperative learning. There were no consistent results due to the gender of the student, nor to the site or academic level of the students. Overall, experience in cooperative learning appeared to be the primary causative factor for the changes.

Discussion of the results indicated that the outcomes were very parallel to those reported by other researchers. However, this study was the first to show the positive connection between cooperative learning and belor average learners. The discussion examined the changes in academic achievement, self-esteem, and locus of control. This discussion also pointed out the important role that the instructional leader plays in bringing such positive changes to a school site.

Realizing that below average learners constitute nearly half of all classes, studies, such as this, examining approaches that make the educational experience more positive for them are extremely important for the future of educational systems. 
REFERENCES 
Ames, C. (1981). Effects of group reward structures on children's attributions and affect. American Educational Research Journal, 18, 273-288.

Ames, D., Ames, R., \& Felker, D. (1977). Informational and dispositional determinants of children's achievement attributions. Journal of Educational Psychology, 168, 63-69.

Aronson, E., Blaney, N., Stephan, C., Sikes, J., and Snapp, M. (1978). The jigsaw classroom. Beverly Hills, CA.: Sage Publications.

Autry, L. B. \& Langenbach, M. (1985). Locus of control and selfresponsibility for behavior. Journal of Educational Research, $79(2)$, $76-84$.

Ball, A. L. (1982) The secrets of learning styles - your child's and your own. Redbook, 160, 1, 73-76.

Barbe, W. B. and Milone, M. N. (1981). What we know about modality strengths. Educational Leadership, 38, 378-380.

Buttler, K. Learning and teaching style in theory and practice. Maynard, Mass.: Gabriel Systems, Inc., 1984.

Cafferty, E. (1980). An analysis of student performance based upon the degree of match between the educational cognitive style of the teachers and the educational cognitive style of the students. Unpublished doctoral dissertation, University of Nebraska.

California Administrative Code. (1986). Title V administrative regulations. Sacramento, Ca: Author.

California State Department of Education. (1983). Guidelines: Title I. Sacramento, Ca: Author.

Canfield, A. A. and Lafferty, J. C. (1970). Learning styles inventory. Detroit: Hunanics Media (Liberty Drawer).

Carbo, M. (1980). Reading style: Diagnosis, evaluation, prescription. Academic Therapy, $16,1,45-52$.

Carruthers, S. and Young, A. (1980). Preference of condition concerning time in learning environments or rural versus city eighth grade students. Learning Styles Network Newsletter, 1 (2), 1.

Carver, C. \& Scheier, M. (1981). Attention and self-regulation: A control theory approach to human behavior. New York: SpringerVerlan. 
Cavanaugh, D. (1981). Student learning styles: A diagnostic prescriptive approach to instruction. Phi Delta Kappan, 63 (3), 202-203.

Cicourel, A. V., Jennings, S., Jennings, K.H., Jennings, K.C. Leiter, R., Mackay, R., Mehan, $H$ and Roth. D. Language and school performance. New York: Academic Press, 1974.

Copenhaven, R. (1979). The consistency of learning styles. The Teacher Educator, 15, 3, 2-6.

Cornett, Claudia E. What you should know about teaching and learning styles. Bloomington, Ind.: Phi Delta Kappa Educational Foundation, 1983.

Covington, M.V. \& Omelich, C. L. (1984). The trouble with pitfalls: A reply to Weiner's critique of attribution theory. Journal of Educational Psychology, 76(6), 1199-1213.

Crandall, V., Katkovsky, w. Crandall, V. Children's beliefs in their own control of reinforcements in intellectual-academic achievement situations. Child Development, 1965, 36, 91-109.

Cross, Jr., J. A. (1982). Prevalence of internal locus of control in artistically talented students. Unpublished research study, University of Alabama.

DeVries, C. \& Slavin, R. E. (1978). Teams-games-tournaments (TGT): Review of ten classroom experiments. Journal of Research and Development in Education, 12, 18-28.

Dunn, K. Madison Prep: Alternative to teenage disaster. Educational Leadership, 1981,38 (5), 386-387.

Dunn, R. What are you willing to do to teach your students through their styles? Early Years, 1984, 13 (5).

Dunn, R. Learning style: State of the science. Theory Into Practice, $1984,23,1,10-19$.

Dunn, R., Cavanaugh, D., Eberle, B., and Zenhausern, R. (1982) . Henispheric preference: The newest element of learning style. American Biology Teacher, 44 (5), 291-294.

Dunn, R. and Dunn, K. (1972). Practical approaches to individualizing instruction. Englewood Cliffs, New Jersey: Parker Division of Prentice-Hall.

Dunn, R. and Dunn, K. (1979a). Learning styles/teaching styles: Should they? - Could they? - Be matched? Educational Leadership, January, 238-244. 
Dunn, R., Dunn, K. and Price, G. E. (1979b). Identifying individual learning styles. In Student learning styles: Diagnosing and prescribing programs. Reston, Va. National Association of Secondary School Principals, 39-54.

Dunn, R. and Price, G. E. (1980). Identifying the learning style characteristics of gifted children. Gifted Child Quarterly, 24, 1, $33-36$.

Fennema, E. (1982, February). Women and mathematics: State of the art review. Reston, Va.: Equity in Mathematics Core Conference.

Good, T., Grouws, D. \& Ebmeier, H. (1983). Active mathematics teaching. New York, NY: Longman.

Gregorc, A. F. (1979). Learning/teaching styles: Their nature and effects. In Student learning styles: Diagnosing and prescribing programs. (pp. 19-26). Reston, Va. National Association of Secondary School Principals.

Griggs, S. (1981). Diagnostic process: Counseling for individual learning styles. NASSP Bulletin, 65, 447, 23-27.

Guild, P. and Grager, S. (1985). Marching to different drummers. Alexandria, Va. Association for Supervision and Curriculum Development.

Hernandez, N. \& Descamps, J. (1986). Review of factors affecting learning of Mexican-Americans. (ERIC Document Reproduction Service No. ED 267946$)$.

Hudes, S., Saladino, A., and Siegler, D. (1977). Learning style sub-scales and self-concept among high achievement third graders. The Journal, 7, 2, 7-10.

Isaac, S. and Michaels, R. (1983). Statistical and research methods. Los Angeles, Ca.: Stilton Press.

Jerkins, J. M. (1982) Teaching to individual student learning styles. The Administrator, 6 (1), 10-12.

Jensen, A. (1982). Bias in mental testing. Englewood Cliffs, N.J.: Prentice-Hall.

Johnson, D. \& Johnson, R. (1975). Learning together and alone: Cooperation, competition, and individualization. Englewood Cliffs: Prentice-Hall.

Johnson, D. \& Johnson, R. (Eds.) (1984). Structuring cooperative learning: Lesson plans for teachers. Minneapolis, Minn.: Interaction Book Co. 
Johnson, D., Maruyama, G., Johnson, R., Nelson, D., \& Skon, L. (1981). The effects of cooperative, competitive, and individualistic goal structures on achievement: A meta-analysis. Psychological Bulletin, $89,47-62$.

Kagan, S. (1983). Social orientation among Mexican American children: A challenge to traditional classroom structures. In E. E. Garcia, (Ed.), The Mexican American child: Language, cognition, and social development. Tempe, AZ: Center for Bilingual Education, Arizona State University.

Kagan, S. (1985). Cooperative learning resources for teachers. Riverside, Ca.: University of California.

Kagan, S., Zahn, G. L., Widaman, K. F., Schwarzwald, J., \& Tyrell, G. (1985). Classroom structural bias: Impact of cooperative and competitive classroom structures on cooperative and competitive individuals and groups. In R. E. Slavin, S. Sharan, S. Kagan, R. Hertz-Lazarowitz, C. Webb, \& R. Schmuck (Eds.), Learning to cooperate, cooperating to learn (pp. 277-312). New York: Plenum.

Kaley, S. B. (1977). Field dependence-independence and learning styles in sixth graders. Unpublished doctoral dissertation, Hofstra University.

Keefe, J. (1982). Assessing student learning styles: An overview. In Student learning styles and brain behavior. (pp. 35-42). Reston, Va.: National Association of Secondary School Principals.

Kirby, P. Cognitive style, learning style and transfer skill acquisition. Columbus, Oh.: The Ohio State University's National Center for Research in Vocational Education, 1979.

Kolb, D. A. (1971). Organizational psychology. Englewood Cliffs, New Jersey: Prentice-Hall.

Krimski, J. S. (1982). A comparative analysis of matching and mismatching fourth grade students with their learning style preferences for the environmental element of light and their subsequent reading speed and accuracy scores. Unpublished doctoral dissertation, St. John's University.

Letteri, C. A. (1976) Cognitive style: Implications for curriculum. In Curriculum Theory, edited by A. Molnar and John Zahorik. (pp. 100-105). Washington, D.C.: Association for Supervision and Curriculum Development.

Lynch, P. K. (1981). An analysis of the relationships among academic achievement, attendance and the individual learning style time preferences of eleventh and twelfth grade students identified as initial or chronic truants in a suburban New York school district. Unpublished doctoral dissertation, St. John's University. 
McCarmon, H. (1981). Modality integration in remedial and nonremedial readers. In Keefe, G. W. Student learning styles and brain behavior. (pp. 85-90). Reston, Va.: The National Association of Secondary School Principals.

Medley, D. (1977). Teacher competence and teacher effectiveness. Washington, D.C.: American Association of Colleges for Teacher Education, (Eric Document Reproduction Services No. ED 143 629).

Norem-Hebersein, A. \& Johnson, D. (1981). Relationships between cooperative, competitive, and individualistic attitudes and differentiated aspects of self-esteem. Journal of Personality, 49, $415-425$.

Papert, S. (1980). Mindstorms. New York: Basic Books, Inc.

Piers, E.V. (1969). The Piers-Harris children's self-concept scale. Nashville, Tennessee: Counselor Recordings and Tests.

Pizzo, J. (1981). An investigation of the relationships between selected acoustic erivironments and sound, an element of learning styles, as they affect sixth grade students' reading achievement and attitudes. Unpublished doctoral dissertation, St. John's University.

Potterbaum, S. M., Keith, T. Z., \& Ehly, S. W. (1986). Is there a causal relation between self-concept and academic achievement? Journal of Educational Research, 79(3), 140-144.

Price, G. E., Dunn, R., and Dunn, K. (1977). Learning style inventory. Lawrence, Ks: Price Systems.

Price, G. E., Dunn, R., and Sanders, W. E. (1979). Relationship of learning style to self-concept. Clearing House, 53(3), 155-158.

Purkey, W. W. (1969) Project self discovery: Its effect on bright but underachieving high school students. Gifted Child Quarterly, 13, 242-246.

Ramirez, M., and Castaneda, A. (1974). Cultural democracy, bicognitive development and education. New York: Academic Press.

Rosenshine, B. (1979). Content, Time and direct instruction. In P. L. Peterson \& H. J Walberg (Eds.), (158-165). Research on teaching: Concepts, findings, and implications. Berkely, CA: McCutchan Publishing Co.

Rotter, J. B. (1975). Some problems and misconceptions related to the construct of internal versus external locus of control of reinforcement. Journal of Consulting and Clinical Psychology, 43, 56-57. 
Scheirer, M. A. \& Kraut, R. E. (1979). Increasing educational achievement via self concept change. Review of Educational Research, $1979,49,131-150$.

Sharan, Shlomo. (1980). Cooperative learning in small groups: Recent methods and effects on achievement, attitudes and ethnic relations. Review of Educational Research, 50, 241-71.

Sharan, S., Kussell, P., Hertz-Lazarowitz, R., Bejarano, Y., Raviv, S., \& Sharan, Y. (1984). Cooperative learning in the classroom: Research in desegregated schoo].5. Hillsdale, NY: Erlbaum.

Shavelson, R. J., \& Bolus, R. (1982). Self concept: The interplay of theory and methods. Journal of Educational Psychology, 74, 3-17.

Shea, T. C. (1983). An investigation of the relationships among preferences for the learning style element of design, selected, instructional learning environments and reading test achievement of ninth grade students to improve administrative determinations concerning effective educational facilities. Unpublished doctoral dissertation, St. John's University.

Slavin, R. E. (1977). How student learning teams can integrate the desegregated classroom. Integrated Education, 15(6), 56-58.

Slavin, R. E. (1978). Student teams and achievement divisions. Journal of Research and Development in Education, 12, 39-49.

Slavin, R. E. (1979). Effects of biracial learning teams on cross-racial friendships. Journal of Educational Psychology, 71, 381-387.

Slavin, R. E. (1980a). Cooperative learning. Review of Educational Research, 59, 315-342.

Slavin, R. E. (1980b). Using student learning. Baltimore, Md.: The Johns Hopkins University.

Slavin, R. E. (1983). Student team learning: An overview and practical guide. Washington, DC: National Education Association.

Slavin, R. E. (1985). Cooperative learning: Applying contact theory in desegregated schools. Journal of Social Issues, 41(3), 45-62.

Slavin, R. E., Leavy, M., \& Madden, N. (1984). Combining cooperative learning and individualized instruction: Effects on students mathematics achievement, attitudes and behaviors. Elementary School Journal, 84, 409-422.

Stewart, E. D. (1981). Learning styles among gifted/talented students: Instructional technique preferences. Exceptional Children, 48(2), 134-138. 
Trautman, P. (1979). An investigation of the relationship between selected instructional techniques and identified cognitive style. Unpublished doctoral dissertation, St. John's University.

Van Dalen, D. B. (1973). Understanding educational research. New York: McGraw-Hill.

Virostko, J. (1983). An analysis of the relationships among student academic achievement in mathematics and reading. Unpublished doctoral dissertation, St. John's University.

Wasson, F, R, (1980). A comparative analysis of styles and personality characteristics of achieving and underachieving gifted elementary students. Unpublished doctoral dissertation, Florida State University.

Webb, N. M. (1984). Sex differences in interaction and achievement in cooperative small groups. Jourmal of Educational Psychology, 76(1), 33-44.

Weiner, B. (1972a). Attribution theory, achievement motivation, and the educational process. Review of Educational Research, 42, 203-215.

Weiner, B. (1972b). Achievement motivation and attribution theory. Morristown, NJ: General Learning Press.

Winer, B. J. (1962). Statistical principles in experimental design. New York: McGraw-Hill.

Wingo, L. H. (1980). Relationships among locus of motivation, sensory modality and grouping preferences of learning style to basic skills test performance in reading and mathematics. Unpublished doctoral dissertation, Memphis State University.

Wylie, R. (1979). The self-concept: Theory and research on selected topics (Vol, 2). Lincoln, NE: University of Nebraska Press.

Yager, S. (1986). The impact of group processing on achievement in cooperative learning groups. Journal of social Psychology, 126(3), 389-397. 
Appendices

Reproduced with permission of the copyright owner. Further reproduction prohibited without permission. 


\section{PLEASE NOTE:}

Copyrighted materials in this document have not been filmed at the request of the author. They are available for consultation, however, in the author's university library.

These consist of pages:

\begin{tabular}{ll} 
APPENDIX A: & $131-133$ \\
\hline APPENDIX B: & $135-137$ \\
\hline
\end{tabular}

\section{University \\ Microfilms \\ International}

300 N. ZEEB RD.. ANN ARBOR, MI 48106 (313) 761.4700 
Appendix A

Intellectual Achievement Responsibility Questionnaire 
Appendix B

The Self-Esteem Inventory 
Appendix C

Parent Permission Letter 
March 15, 1986

\section{Dear Parents:}

During the month of April, 1986, some of our third grade teachers will be evaluating some new approaches to the teaching of spelling. As part of this effort, the children will be taking some tests prior to the implementation of the new approaches and after their implementation.

Three tests will be administered. The first is a test that evaluates why children believe they do or do not do well in school. The name of this test is the Intellectual Achievement Responsibility Questionnaire. The second test is a questionnaire that attempts to examine how children feel about school and themselves. Its name is the Self-Esteem Inventory. The last test is the Learning Styles Inventory. It will be given to help the teachers decide what is the best way to group students for spelling instruction.

These tests, as well as the regular spelling tests, will allow the teachers to determine if these approaches worked as well as the regular approach to spelling or if they worked better. If you do not want your child to participate in the testing, please complete the bottom part of this form and return it to his/her teacher by April 10, 1986.

If you have any questions about this effort, please feel free to contact me at school between the hours of $8 \mathrm{a} . \mathrm{m}$. and $4: 30 \mathrm{p} . \mathrm{m}$.

Sincerely

(The School Principal)

I do not want my child, to participate in the testing described in this letter.

Signed:

Relationship: 


\section{PLEASE NOTE:}

Copyrighted materials in this document have not been filmed at the request of the author. They are available for consultation, however, in the author's university library.

These consist of pages:

\begin{tabular}{ll} 
APPENDIX A: & $131-133$ \\
\hline APPENDIX B: & $135-137$ \\
\hline
\end{tabular}

\section{University \\ Microfilms \\ International}

300 N. ZEEB RD.. ANN ARBOR, MI 48106 (313) 761.4700 